JULIANA DE AGUIAR GROSSI

TRATAMENTO RESTAURADOR ATRAUMÁTICO COMO OPÇÃO RESTAURADORA PARA HIPOMINERALIZAÇÃO MOLAR-INCISIVO

BRASÍLIA 


\section{UNIVERSIDADE DE BRASÍLIA \\ FACULDADE DE CIÊNCIAS DA SAÚDE \\ PROGRAMA DE PÓS-GRADUAÇÃO EM CIÊNCIAS DA SAÚDE}

JULIANA DE AGUIAR GROSSI

TRATAMENTO RESTAURADOR ATRAUMÁTICO COMO OPÇÃO RESTAURADORA PARA HIPOMINERALIZAÇÃO MOLAR-INCISIVO

Dissertação apresentada como requisito parcial para a obtenção do Título de Mestre em Ciências da Saúde pelo Programa de PósGraduação em Ciências da Saúde da Universidade de Brasília.

Orientadora: Prof ${ }^{\mathrm{a}} \mathrm{Dr}^{\mathrm{a}}$ Soraya Coelho Leal

BRASÍLIA 


\title{
TRATAMENTO RESTAURADOR ATRAUMÁTICO COMO OPÇÃO RESTAURADORA PARA HIPOMINERALIZAÇÃO MOLAR-INCISIVO
}

\begin{abstract}
Dissertação apresentada como requisito parcial para a obtenção do Título de Mestre em Ciências da Saúde pelo Programa de Pós-Graduação em Ciências da Saúde da Universidade de Brasília.
\end{abstract}

\section{BANCA EXAMINADORA}

Soraya Coelho Leal (Presidente)

Universidade de Brasília

Fernanda Cristina Pimentel Garcia (Membro) Universidade de Brasília

Denise de Lima Costa Furlanetto (Membro)

Universidade de Brasília

Eliana Mitsue Takeshita (Suplente)

Universidade de Brasília 
Dedico essa Dissertação aos meus pais, PLÍNIO GROSSI E LUZIA MARIA DE AGUIAR GROSSI.

Gratidão é a palavra para expressar tudo que fizeram e fazem por mim. Desde os primeiros passos até a vida adulta, poder compartilhar minha vida com vocês é um presente de Deus, que me permitiu nascer num lar cheio de amor e paz. Por onde vou levo o orgulho de ser sua filha, o exemplo de ser humano que aprendi dentro de casa e a vontade incansável de ajudar o próximo através de minha profissão.

À minha querida tia, in memorian, MARIA DA GLÓRIA GROSSI, Por todo amor, dedicação à família GROSSI, incentivo e torcida para meu desenvolvimento profissional. Se estivesse fisicamente aqui, tenho certeza que compartiharia mais esse momento comigo, mas sinto que de onde está continua vibrando e zelando por nossa família. Que prazer ter te encontrado 


\section{AGRADECIMENTOS}

Este trabalho traz pra mim um significado enorme. Coroa uma conquista que sempre sonhei realizar e também representa, de certa forma, uma superação pessoal frente aos desafios que enfrentei desde o início do Mestrado.

Agradeço a Deus, o Criador de tudo e de todos. Sua inteligência suprema que tudo vê e sabe e que entrego minha vida e minhas decisões. Ele sabe o que é melhor pra mim e eu só posso confiar minha vida a Ele.

A minha família, por tanto amor ofertado e compreensão. Especial agradecimento aos meus pais, que me deram o dom da vida - Luzia e Plínio. Se cheguei onde estou hoje é pelo esforço, amor, paciência e dedicação que vocês tiveram e eu sempre levarei esse exemplo comigo. Gratidão eterna.

Agradeço os professores da minha graduação em Odontologia, que me ensinaram como ser uma Cirurgiã-Dentista qualificada e comprometida com a ciência e não com o empirismo. Onde tudo começou: FOA - UNESP- Araçatuba, minha eterna gratidão.

A minha orientadora Prof ${ }^{-}$Dr ${ }^{-}$Soraya Coelho Leal, gratidão por ter aberto as portas da Universidade de Brasília para mim e ter me aceitado como sua aluna. É uma fonte de inspiração não só pela bela profissional que é, reconhecida internacionalmente, mas como exemplo de ser-humano, incansável em ajudar o próximo e idealista nata. Ganhei de presente não só uma orientadora, mas uma amiga para a vida. Esteja certa que pode contar comigo.

A equipe de professores da UnB que convivi durante esses anos de Mestrado, em especial Professora Simone Otero, Ana Paula Dias Ribeiro, Leandro Hilgert: vocês me inspiram a ser uma profissional melhor.

À amiga, Renata Nunes Cabral, por toda a paciência, disponibilidade e ajuda, desde o início do projeto até o final. Você sempre esteve pronta para me ajudar. Aprendi muito com você e te agradeço muito. Conte comigo sempre.

A Professora Dra Ana Paula Dias Ribeiro por ter realizado a análise estatística desse trabalho.

Agradeço as Professoras Dra. Denise Furlanetto, Fernanda Garcia, Eliana Takeshita por aceitarem fazer parte da banca de minha defesa de Mestrado. É uma honra poder ter profissionais tão bem qualificadas compondo minha banca. 
Ao grupo de pesquisadoras que trabalham junto com a professora Soraya Leal, em especial, Tereza, Maria José, Ana Luiza, Junia, Daniele, Isadora. Um verdadeiro time focado em pesquisa e pronto a ajudar a qualquer momento. Foi um privilégio conviver com cada uma de vocês.

À minha amiga Patrícia Bastos, meu agradecimento especial. Foi você, querida amiga, que deu o pontapé para esse Mestrado. Uma amizade verdadeiramente pura, onde uma torce pela outra. Coisa rara de se ver hoje em dia.

À Secretaria de Educação do Distrito Federal (DF) e a cada uma das diretoras das respectivas escolas que fizeram parte do estudo, por nos receberem de portas abertas, facilitando o desenvolvimento do trabalho.

Aos meus colegas de trabalho, em especial, Paulo e Gerlídia, pela compreensão e apoio nos momentos difíceis, o meu muito obrigado.

Ao colega Dr. Marcelo Nogueira Aucélio, cirurgião dentista do Hospital Regional do Paranoá (HRPa) que muito nos ajudou durante esse estudo.

Ao colega Dr. César Augusto de Melo e Silva pela atenção e paciência nos ensinamentos de estatística.

A empresa Duflex do Brasil - SSWhite - com sede no Rio de Janeiro que gentilmente nos cedeu alguns KITS de ART para a realização desta pesquisa.

A empresa GC que nos cedeu gentilmente o material restaurador utilizado nessa pesquisa.

Às crianças do Paranoá e suas famílias, que confiaram no nosso trabalho. Sou muito grata a todos vocês.

Por fim, todos meus amigos, em especial Paula Lorena, que com paciência e carinho, entenderam os momentos que tive que me ausentar da companhia deles para dedicar a esse projeto. Parafraseando Vinícius de Moraes: "A gente não faz amigos, reconhece-os". 
"Quando vejo uma criança, ela inspira-me dois sentimentos: ternura pelo que é, e respeito pelo que pode vir a ser." 


\section{RESUMO}

Hipomineralização molar incisivo (HMI) é um defeito qualitativo do esmalte dentário envolvendo 1 ou até 4 primeiros molares permanentes, associado ou não a defeitos nos incisivos permanentes. Clinicamente, os dentes apresentam esmalte poroso nas áreas demarcadas que, frequentemente, apresentam fratura de esmalte pós-eruptiva, expondo dentina e facilitando o desenvolvimento de cárie. A literatura mostra que crianças com HMI recebem mais tratamentos dentários que crianças não afetadas. Além disso, os tratamentos tendem a ser mais invasivos, desafiando o profissional quanto à escolha da melhor opção restauradora. Assim, o objetivo deste trabalho foi avaliar a sobrevida de restaurações realizadas de acordo com o Tratamento Restaurador Atraumático (ART) em primeiros molares afetados por HMI. Para isso, um estudo epidemiológico identificou 1971 escolares dos quais 184 eram portadores de HMI diagnosticadas por meio do critério da Academia Européia de Odontopediatria - EAPD. Destas, 60 crianças apresentavam grau severo de HMI com cárie e sem envolvimento pulpar, das quais 44 compuseram a amostra desse estudo. Os tratamentos foram realizados na escola por um único dentista utilizandose ionômero de vidro de alta viscosidade (Equia Forte, GC America) de acordo com a técnica ART. Após 6 e 12 meses, um examinador independente avaliou as restaurações por meio do critério ART modificado. Foram realizadas análise descritiva dos dados e regressão logística $[\mathrm{P} \leq 0.05$; $95 \%$ intervalo de confiança]. Foram tratados 60 dentes em um total de 44 crianças, sendo 24 meninas $(54,54 \%$ ) e $20(45,45 \%)$ meninos com idade média de 10,55 $( \pm 1,25)$ anos. Considerando o número de superfícies, 29 (48,3\%) das restaurações envolveram 1 face, 20 (33,3\%) duas e $11(18,4 \%)$ mais que duas faces. Quanto à extensão das restaurações, 25 (41\%) apresentavam lesão em dentina sem enfraquecimento de cúspide, 23 (37,7\%) com lesão em dentina e enfraquecimento de cúspide, e 13 (21,3\%) com lesões em dentina com destruição de uma ou mais cúspides. A anestesia foi necessária em 4 casos. A taxa de sucesso após 6 e 12 meses foi de $98,3 \%$, observando-se falhas em somente 1 restauração. Uma análise bivariada mostrou que dentre as variáveis idade, sexo, dente, número de faces e extensão das cavidades apenas a variável número de faces mostrou-se se estatisticamente associada a falhas $(p=0,016)$, uma 
vez que a mesma ocorrereu em dente com três ou mais faces envolvidas. Porém, no modelo de regressão logística no qual todas as variáveis foram incluídas, não se apresentou significativo $(p=0,276)$. Diante do exposto, concluiu-se que a maioria dos dentes com HMI não apresentou necessidade de tratamento, e aqueles com necessidade de tratamento, requerem majoritariamente restaurações diretas. Dentes afetados por HMl apresentam cavidades atípicas, uma vez que foram associadas à quebra pós-eruptiva, não seguindo um padrão comum definido como ocorre para cárie dentária. As restaurações ART, colocadas em campo, para restauração em primeiros molares permanentes afetados por HMI, mostraram-se eficazes para preservação da estrutura dentária desses dentes. Restaurações envolvendo três ou mais faces tiveram maior chance de falhar no período de 12 meses.

Palavras-chave: Hipomineralização molar incisivo, tratamento restaurador atraumático, cimento de ionômero de vidro, tamanho da cavidade, taxa de sobrevida. 


\section{ABSTRACT}

Molar-Incisor Hypomineralisation $(\mathrm{MIH})$ is a qualitative enamel defect that involves hypomineralisation of 1 to 4 first permanent molars (FPM) associated or not with affected permanent incisors. Clinically, MIH teeth present with demarcated enamel opacities that very often envolves post eruptive breakdown (PEB) wich exposes dentine facilitating caries development. The literature shows that children with $\mathrm{MIH}$ receive more dental treatments than those who are not affected. Moreover, treatments tend to be more invasive, challenging the professional with respect to the best restorative approach. Thus, the aim of this study was to evaluate the survival rate of Atraumatic Restorative Treatment (ART) restorations in first permanent molars affected by $\mathrm{MIH}$. An epidemiological survey detected 1971 schoolchildren from whom 184 individuals were diagnosed with MIH using the EAPD criteria. From this total, 60 schoolchildren presented severe $\mathrm{MIH}$ molars associated to carious dentine lesions without pulp involvement, from wich 44 composed the sample included in this trial. Treatments were performed by one trained dentist using the ART approach at school premises. A high viscosity glass ionomer cement (GIC) restorative system (Equia Forte, GC®) was used according to ART technique. Treatments were evaluated after 6 and 12 months by an independent examiner using the ART modified criteria. Data analysis involved descriptive statistics and logistic regression [P $\leq 0.05 ; 95 \%$ confidence interval $(95 \% \mathrm{Cl})]$. A total of 60 teeth were treated in 44 children, 24 (54.54\%) girls and 20 (45.45\%) boys with a mean age of $10.55( \pm 1.25)$ years. In regard to the number of surfaces involved in the restorations, $29(48.3 \%)$ of them involved one surface, 20 (33.3\%) two and 11 (18.4\%) more than two surfaces. Considering cavity size of the restorations, 25 (41\%) presented dentine cavitation without cusp weakness, 23 (37.7\%) large dentine cavitation with cusp weakness and $13(21.3 \%)$ large dentine cavitation with one or more cusp breakdown. Only 4 children required the use of local anaesthesia. A survival rate, after 6 and 12 months of $98,3 \%$ was observed, as only one restoration failed. A bivariate analysis showed that variables age, gender, tooth, number of surfaces and cavity size only 'number of surfaces' was considered significant $(\mathrm{p}=0.016)$ as all failures occurred in restorations of three or more surfaces. However, in a logistic regression model, with 
all variables included, it were not considered significant $(p=0.276)$ as all the failures occurred in one restorations of three or more surfaces. From this preliminary data, it is possible to conclude that the majority of the teeth diagnosed with MIH didn't require treatment and those who need it, direct restorations were indicated. $\mathrm{MIH}$ teeth have a different pattern of cavities design (atypical cavities) resulting from post eruptive enamel breakdown. The ART restorations, performed in the field, showed to be an effective treatment to preserve first permanent molars affected by $\mathrm{MIH}$. Restorations with three or more surfaces had a higher chance to fail.

Keywords: $\mathrm{MIH}$; Atraumatic Restorative Treatment, glass ionomer, cavity size, survival rate. 


\section{LISTA DE ILUSTRAÇÕES}

Figura 1 - a) Hipoplasia do esmalte dentário nos elementos 11,21,41; b) Opacidade demarcada de cor amarelada na face oclusal do 36; c) Opacidade difusa gereralizada e associada à porosidade nos elementos 11 e 21 sugestiva de fluorose dentária; d) Amelogênese Imperfeita...... .23

Figura 2 - Fluxograma com o número de crianças/dentes elegíveis e os que compuseram a amostra do estudo. .45

Figura 3 - Porcentagem de crianças atendidas de acordo com a escola. 46 


\section{LISTA DE TABELAS}

Tabela 1 - Critério para registro da HMI, seus códigos e classificação de acordo com a gravidade, adaptado por Dra. Rita de Cássia Loiola

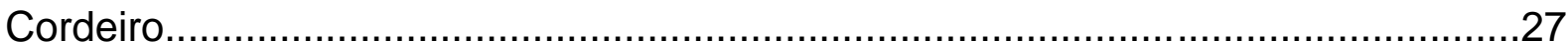

Tabela 2 - Critério Nyvad utilizado para diagnóstico de cárie dentária ...................40 Tabela 3 - Critério ART Modificado, seus códigos e a definição de sucesso e falha.

Tabela 4 - Sobrevida das restaurações de ART nos períodos de 6 e 12 meses

Tabela 5 - Razão de chance e intervalos de confiança da sobrevida das restaurações de acordo com as diferentes variáveis independentes................................................................................... 49

Tabela 6 - Características das famílias incluídas no estudo considerando renda, nível de escolaridade e condições de vida. .50 


\section{LISTA DE ABREVIATURAS}

ART - Tratamento Restaurador Atraumático

CAPES- Coordenação de Aperfeiçoamento de Pessoal de Nível Superior CIV - Cimento de ionômero de vidro

DDE- Defeitos de Desenvolvimento de Esmalte

DF- Distrito Federal

EAPD- European Academy of Paediatric Dentistry

$\mathrm{HMI}$ - Hipomineralização Molar-incisivo

HUB - Hospital Universitário de Brasília

IBGE - Instituto Brasileiro de Geografia e Estatística

PEB - Quebra de esmalte pós-erupção (enamel post-eruptive breakdown)

SUS - Sistema Único de Saúde

UNB - Universidade de Brasília 


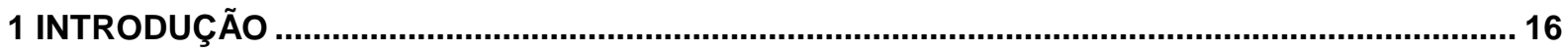

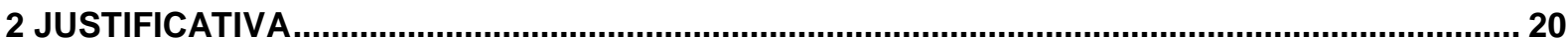

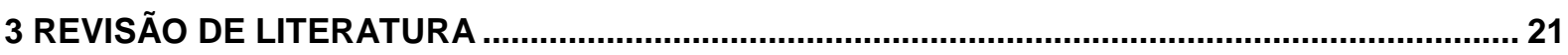

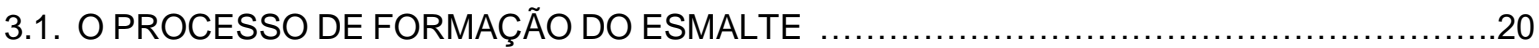

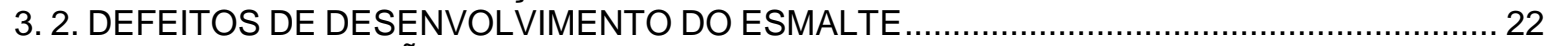

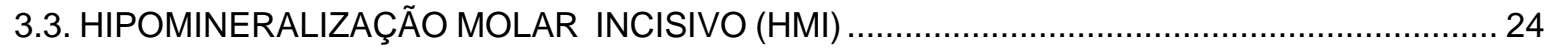

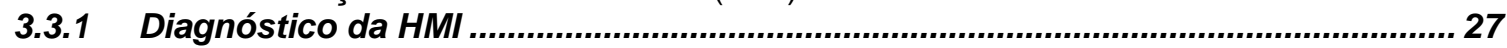

3.3.2 Diagnóstico Diferencial entre HMI, Hipoplasia, Amelogênese Imperfeita e Fluorose

3.4.TRATAMENTO RESTAURADOR ATRAUMẢTICO

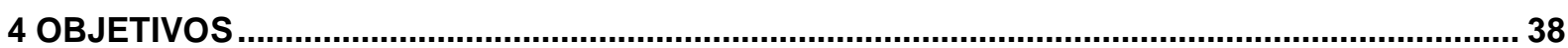

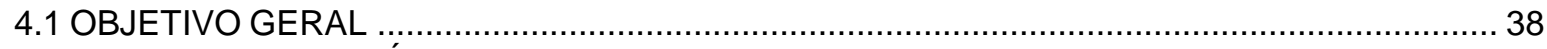

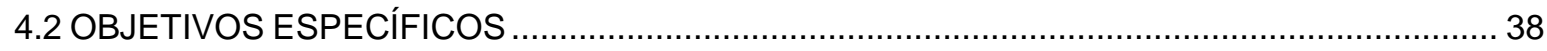

5 MATERIAL E MÉTODOS

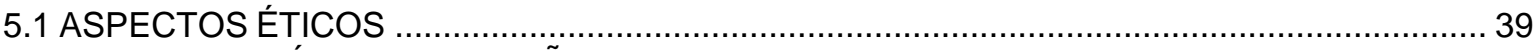

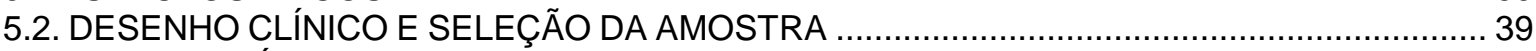

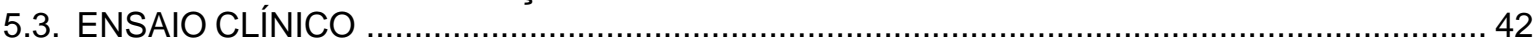

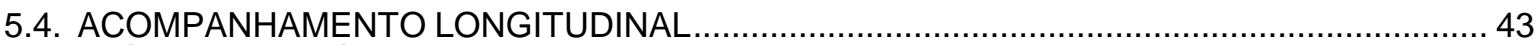

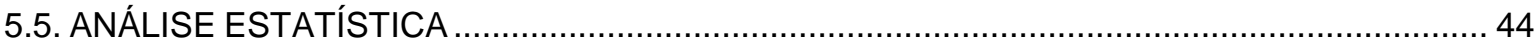

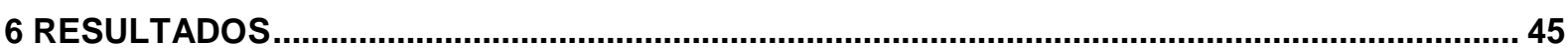

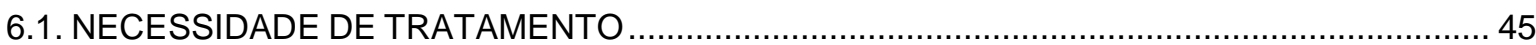

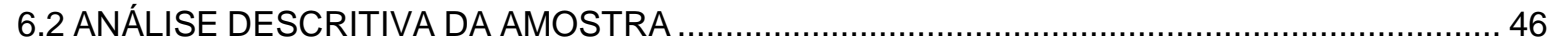

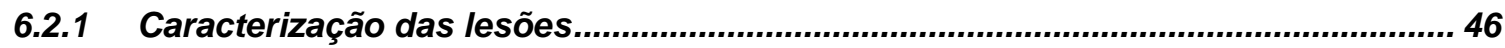

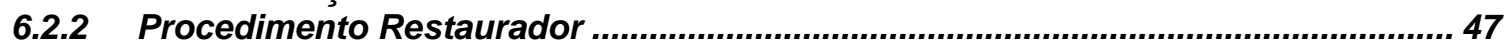

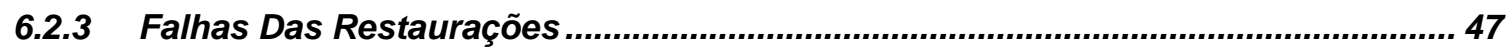

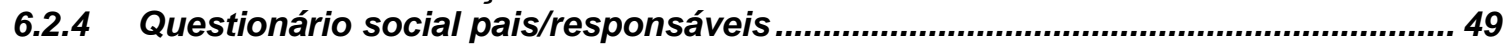

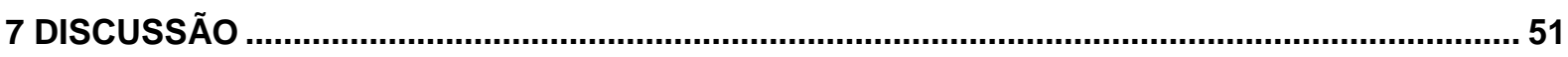

8 CONCLUSÃO

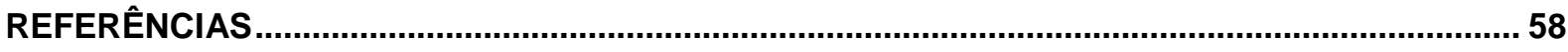

ANEXOS

ANEXO A - DOCUMENTO DE APROVAÇÃO NO COMITÊ DE ÉTICA EM PESQUISA …............ 71

ANEXO B - TERMO DE CONSENTIMENTO LIVRE E ESCLARECIDO ….............................. 73

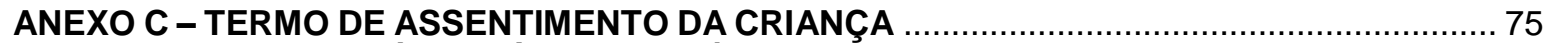

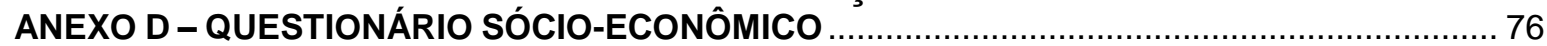

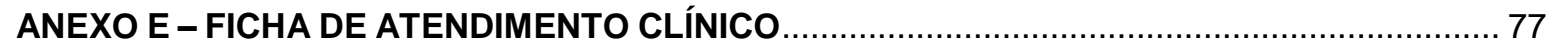




\section{INTRODUÇÃO}

É cada vez mais comum a observação de defeitos de formação do esmalte, cuja presença pode influenciar no desenvolvimento de lesões de cárie e, consequentemente, no seu tratamento. Como os dentes fazem parte de todo um sistema biológico, é importante estar atento ao fato de que doenças sistêmicas podem interferir negativamente na formação do elemento dentário.

Nesse aspecto, vários defeitos de desenvolvimento do esmalte (DDE) foram catalogados e devidamente descritos pela comunidade científica, geralmente classificados como hipoplasias e hipomineralizações $(3,4,22,23,25)$. A hipoplasia é um defeito quantitativo, consequência de uma deficiência na secreção de matriz formadora do esmalte, que resulta na redução da espessura do esmalte formado (5, 22). Já a hipomineralização é um defeito qualitativo, que não afeta a quantidade de matriz secretada, mantendo normal a espessura do tecido, e caracteriza-se pela translucidez anormal do esmalte, também conhecida como opacidade do esmalte (6).

$\mathrm{Na}$ década passada, um defeito de desenvolvimento sem associação com fluorose dentária foi descrito por Weerheijm et al (2001) (1). A afecção denominada Hipomineralização Molar incisivo (HMI) é definida como uma alteração de desenvolvimento relativamente comum, caracterizada por defeitos na mineralização do esmalte dentário nos primeiros molares e incisivos permanentes. Pode acometer de 1 a 4 primeiros molares permanentes, com ou sem envolvimento dos incisivos permanentes. Para um indivíduo ser diagnosticado como portador de HMI, este deve possuir ao menos um primeiro molar permanente afetado. Caso a opacidade esteja presente em um incisivo isoladamente, este não se enquadraria na definição de $\operatorname{HMI}(1,2)$.

A literatura mostra que os defeitos no esmalte dentário de dentes afetados por HMI resultam de uma variedade de fatores ambientais, interagindo sistemicamente no período de desenvolvimento natal, perinatal e pós-natal da criança, assim como condições médicas comuns na infância, a citar: catapora, febre alta, uso frequente de antibióticos, entre outros $(9,10,21,26,39)$.

Clinicamente as lesões se apresentam como demarcações pontuais opacas envoltas por esmalte sadio $(1,24)$. Nessas demarcações, o esmalte possui 
espessura normal, porém de qualidade inferior em relação ao esmalte íntegro devido à presença de porosidades que se tornam progressivamente mais graves de acordo com a cor, sendo que as opacidades mais escuras apresentam menor conteúdo mineral $(20,21)$. Frequentemente, observa-se a quebra pós-eruptiva do esmalte afetado devido à ação de forças mastigatórias $(1,19)$ o que, por conseguinte, leva a um aumento de sensibilidade na região ao expor a dentina abaixo do esmalte fraturado.

De acordo com a literatura, crianças com HMl apresentam 10 vezes mais chances de serem submetidas ao retratamento que crianças não afetadas por essa condição (11,29). Devido à grande porosidade do esmalte afetado e, consequentemente, baixa resistência mecânica, a HMI é considerada um fator de risco para a cárie dentária em populações com baixa prevalência de cárie $(1,17,18)$. Dificuldade no atendimento da criança, bem como acúmulo de placa e rápido desenvolvimento de cárie são fatores que desafiam o manejo clínico da $\mathrm{HMI}$ $(7,8,27,31,32,39)$.

Quimicamente, o esmalte defeituoso apresenta-se com grande quantidade de carbono, baixa quantidade de cálcio e fósforo quando comparado ao esmalte sadio $(1,24)$. Jalevik et al (2001) (3), observaram que a presença de grandes porosidades na microestrutura do esmalte hipomineralizado, afeta a performance adesiva das restaurações em resina composta, levando à perda precoce de restaurações realizadas com esse material em dentes com HMI. Assim, esses dentes acabam por necessitar de repetidas intervenções, onerando o tratamento e dificultando o manejo da criança pelo profissional $(11,12,24)$.

Muitas opções de tratamento estão descritas para o manejo clínico de dentes com HMI que já apresentam quebra pós-eruptiva como, por exemplo, coroas de aço (14), o uso da resina composta, e do cimento de ionômero de vidro (CIV) $(15,16)$ e a exodontia seguida de ortodontia. Porém, observa-se falta de consenso na literatura quanto à melhor opção restauradora para tal condição $(19,24,29,33)$.

De fato, o tratamento restaurador de dentes afetados por HMI é um desafio, haja vista as particularidades estruturais e técnicas acima elencadas. Adicionalmente, somam-se a esses fatores as dificuldades inerentes à saúde pública brasileira. Sabe-se que, de maneira geral, o acesso ao tratamento dentário por parte daqueles que dependem do serviço público é difícil e, usualmente, implica num longo tempo de espera (83). Assim, diante desse quadro, pergunta-se qual a melhor 
forma de evitar que dentes com HMl sejam extraídos em função do limitado acesso aos cuidados de saúde de grande parte da população brasileira?

Com o objetivo de responder tal indagação, buscou-se avaliar a efetividade do Tratamento Restaurador Atraumático (ART) como forma de manejo restaurador de dentes com HMI apresentando exposição de dentina/restauração não satisfatória e cárie associada. Para tanto, a população alvo foi composta por escolares de uma comunidade socialmente vulnerável que possuem restrito acesso ao Sistema Único de Saúde (SUS). 


\section{JUSTIFICATIVA}

A HMI é uma condição relativamente comum, com prevalência variando de 20 a 40\% dependendo da população estudada (13). Quando diagnosticada, exige uma abordagem rápida e eficiente uma vez que, na presença de quebra pós-eruptiva, observa-se rápida progressão de cárie $(7,8,27)$.

Além disso, características estruturais do esmalte afetado como aumento da porosidade, maior quantidade de carbono e menor quantidade de mineral $(12,40,41,42)$ desafiam o clínico na escolha da melhor opção restauradora, principalmente, quando se opta por materiais adesivos.

Lançando um olhar para a saúde pública brasileira, apesar de todos os avanços alcançados nas últimas décadas (83,85), são inquestionáveis as dificuldades que os usuários enfrentam na obtenção de pronto acesso ao tratamento odontológico. Dessa forma, a busca por um protocolo de tratamento que se adeque à realidade de crianças acometidas por HMI socialmente vulneráveis é, sem dúvida, de relevância social $(19,24,29,33)$. Assim, este estudo propõe uma alternativa de tratamento que objetiva evitar que crianças tenham dentes extraídos precocemente. Muito provavelmente, após essa primeira abordagem, um tratamento mais definitivo, como por exemplo o uso de coroa protética, seja necessário. Entretanto, até lá, o dente afetado por HMI poderá ser mantido por meio de restaurações mais conservadoras. 


\section{REVISÃO DE LITERATURA}

\section{1. O PROCESSO DE FORMAÇÃO DO ESMALTE}

O órgão do esmalte é responsável pela formação do esmalte dentário, num processo conhecido como amelogênese (47). Este é um processo de múltiplas etapas e intercorrências podem ser observadas em qualquer uma delas. Em geral, o esmalte dentário desenvolve-se em dois principais estágios: secreção e maturação. Durante a fase secretória, a matriz do esmalte é depositada e parcialmente mineralizada porém, a maior parte da mineralização da matriz ocorre durante a fase subsequente de maturação (45).

As alterações do esmalte dentário podem ser relativas a um defeito quantitativo (diminuição da espessura) ou qualitativo (hipomineralizações). Os tipos mais comuns de alterações na amelogênese resultam em: hipoplasia, opacidade difusa e opacidade demarcada (47).

Fatores locais ou sistêmicos que interferem na formação normal da matriz provocam defeitos e irregularidades no esmalte, denominados hipoplasias do esmalte. Fatores que interferem na mineralização e na maturação do esmalte produzem uma condição denominada hipomineralização do esmalte (46).

Assim, é importante conhecer a cronologia de formação dos elementos dentários, para que se possa correlacionar a presença de defeitos a fatos ocorridos nesse período. As coroas dos dentes decíduos desenvolvem-se entre a 15ª semana de gestação e o primeiro ano de vida, enquanto o desenvolvimento das coroas dos permanentes estende-se desde aproximadamente os seis meses pré-natal até os 15 anos de idade (45). A duração do estímulo sobre os ameloblastos tem um grande impacto na localização e aspecto do defeito no esmalte. Como consequência, o esmalte formado retrata todas as agressões significativas sofridas ao longo do desenvolvimento do dente (45). 


\section{2. DEFEITOS DE DESENVOLVIMENTO DO ESMALTE (DDE)}

Os ameloblastos são células extremamente sensíveis aos estímulos externos, e muitos fatores podem resultar em anomalias do esmalte (45). Os fatores associados aos defeitos do esmalte descritos na literatura podem ser agrupados de acordo com a origem em sistêmicos e locais (45).

Dentre os fatores etiológicos dos DDE de origem sistêmica, destacam-se: traumas relacionados ao nascimento, alterações químicas (flúor, chumbo, tetraciclina, etc), anomalidades cromossômicas (trissomia do 21), infecções (caxumba, catapora, sarampo, infeções respiratórias, etc), doenças hereditárias (epidermólise bolhosa, galactosemia, fenilcetonúria, entre outras), desnutrição (deficiência de vitamina $A, D$, deficiência nutricional generalizada), alterações metabólicas (hipocalcemia, hipotireoidismo, hipoparatireoidismo, doença renal, entre outras) e alterações neurológicas (paralisia cerebral, retardo mental, defeitos de audição sensorioneurais) (45).

Como fatores locais aparecem o trauma mecânico local (quedas, ventilação mecânica neonatal, cirurgias, etc), queimadura elétrica, irradiação e infecção local (doença inflamatória periapical) (45).

As alterações na amelogênese são usualmente descritas como DDE (47) e são elas:

- Hipoplasia - é uma alteração do desenvolvimento do esmalte que está associada à redução da espessura do mesmo. $O$ esmalte pode apresentar aparência opaca ou translúcida. Pode ocorrer na forma de fosseta ou sulco, ambos de forma única ou múltipla e, também, haver ausência parcial ou completa de esmalte dentário sobre uma área considerável de dentina (47) (Figura 1a).

- Opacidade demarcada - é uma alteração na translucidez do esmalte que apresenta superfície afetada de aspecto liso, espessura normal e uma delimitação clara com o esmalte normal adjacente. Pode apresentar coloração branca, creme, amarela ou castanha. Pode apresentar locais de desintegração do esmalte dentário pós-irrupção (47). Um exemplo dessa condição é a hipomineralização molar-incisivo (Figura 1b). 
- Opacidade difusa - é uma alteração na translucidez do esmalte na qual o esmalte defeituoso possui espessura normal. Esta alteração de translucidez do esmalte pode ocorrer em vários graus e com uma distribuição linear, contínua ou na forma de manchas. Não existe delimitação clara da porção afetada com o esmalte normal adjacente. Parte ou todo o esmalte poderá ser afetado e a escala de gravidade é baseada na extensão e profundidade em que o local foi afetado (47). A fluorose dentária é um exemplo de opacidade difusa (Figura 1c).

- Amelogênese Imperfeita - é uma má formação do esmalte dental que pode afetar ambas as dentições, afetando todos os dentes e é transmitida geneticamente. É, portanto, uma alteração hereditária estando restrita à estrutura do esmalte sem a presença de outros comprometimentos sistêmicos aparentes (47). A anomalia ocorre na população em geral, na proporção de 1 em 14.000 a 1 em 16.000, exibindo formas e aparências variadas (46). No tipo hipoplásico, a matriz do esmalte parece ser formada imperfeitamente; embora ocorra a subsequente mineralização na matriz e o esmalte se torne duro; ele é deficiente em quantidade e apresenta superfície áspera, rugosa, com fossetas. No tipo hipomineralizado, a formação da matriz parece ser de espessura normal, mas a mineralização é deficiente e o esmalte é amolecido. Em ambos os tipos, o defeito de esmalte se torna manchado, devido às irregularidades da superfície e à permeabilidade aumentada (46). Já no tipo hipomaturado, a matriz é depositada apropriadamente e começa a mineralizar, porém há um defeito na maturação da estrutura cristal do esmalte (45). Os dentes afetados são normais na forma, porém o esmalte é mais mole que o normal e tende a soltar-se da dentina subjacente. Radiograficamente, o esmalte afetado exibe uma radiodensidade semelhante à da dentina (45) (Figura 1d).

Os DDE apresentam importância clínica significativa, sendo causa de problemas estéticos e sensibilidade dentária $(35,47,48,93,94)$. Portanto, é importante fazer a distinção entre os tipos de defeito, uma vez que o tratamento restaurador para a hipoplasia e hipomineralização, pode variar conforme a extensão e o grau de comprometimento do esmalte dentário (49). 


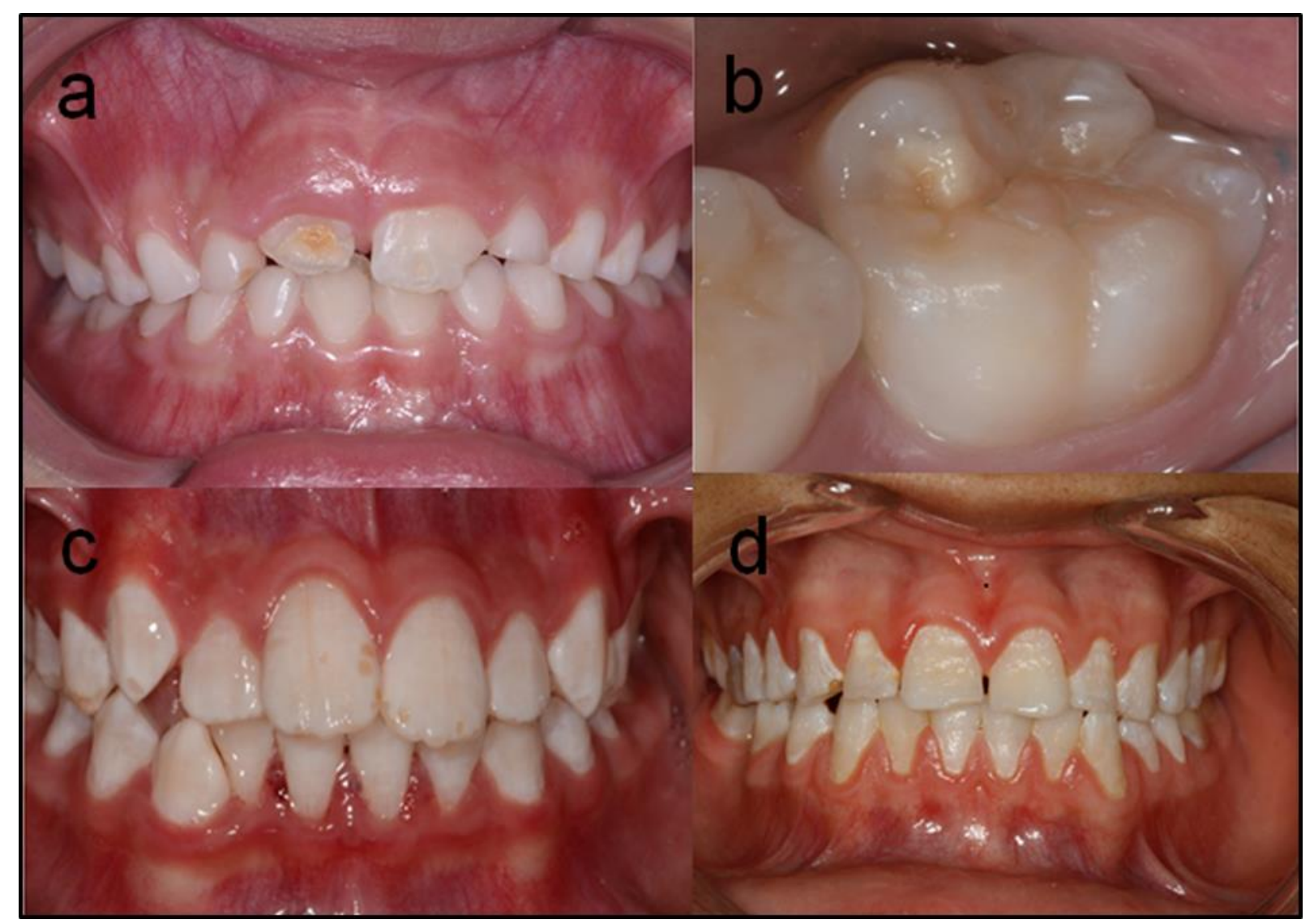

Figura 1. a) Hipoplasia do esmalte dentário nos elementos 11, 21, 41 (Fonte: Dra. Renata Cabral); b) Opacidade demarcada de cor amarelada na face oclusal do 36 (Fonte: Dra. Renata Cabral); c) Opacidade difusa gereralizada e associada à porosidade nos elementos 11 e 21 sugestiva de fluorose dentária (Fonte: Prof. Dra. Soraya Coelho Leal); d) Amelogênese Imperfeita (Fonte: Prof. Dr. Paulo Márcio Yamaguti)

\subsection{HIPOMINERALIZAÇÃO MOLAR INCISIVO (HMI)}

Como já mencionado anteriormente, $\mathrm{HMI}$ é definida, segundo Weerheijm et al (2001), como uma alteração de desenvolvimento do esmalte de origem sistêmica na 
qual opacidades demarcadas estão presentes em pelo menos um dos primeiros molares permanentes podendo, ainda, afetar ou não os incisivos permanentes $(1,5)$.

As opacidades são bem demarcadas permitindo visualizar o limite entre 0 esmalte normal e o afetado, de coloração que varia de branco/amarelo até castanho/amarronzado (5) (figura 1b). Tais opacidades estão mais concentradas nos terços oclusal e médio das coroas dentárias $(51,72)$ e o esmalte das áreas afetadas apresenta-se amolecido e poroso, porém, sem perda de espessura. Chawla et al (2008) (21) sugeriram que as opacidades amarelas/castanhas, por serem mais desorganizadas estruturalmente que as brancas, são mais vulneráveis a fratura de esmalte pós-eruptiva.

Áreas de porosidade de graus variados foram encontradas nas bordas do esmalte afetado com o esmalte sadio (1). Grande concentração de carbono associada a baixos níveis de cálcio e fósforo no esmalte com HMI foram também registrados (1). Acredita-se que esta variação na composição contribui para a menor resistência mecânica do esmalte afetado, uma vez que proporção de cálcio e fósforo no esmalte afetado pela HMl é 1,4 menor do que a encontrada no esmalte normal (11). Adicionalmente à redução do componente mineral, observa-se que o dente com HMI possui maior quantidade de proteínas na sua composição com níveis de amelogeninas similares ao esmalte sadio $(54,96)$. Este fato pode ser utilizado para distinguir a HMI de outros defeitos do esmalte como amelogênse imperfeita e fluorose, que possuem altos teores de amelogeninas na sua estrutura(96).

A avaliação microestrutural do esmalte afetado por HMl indicou que os prismas encontravam-se desorganizados (58), além de apresentarem-se mais delgados, com o espaço interprismático maior em comparação ao esmalte normal. Esse tipo de desarranjo indica que os ameloblastos sofreram injúria durante a fase de maturação da matriz orgânica (58) e não na fase de secreção, como ocorre em outros defeitos do esmalte.

Foi sugerido, ainda, que as opacidades amarelas/marrons são mais porosas que as opacidades brancas por possuírem maior concentração de matéria orgânica (21), e por conseguinte, menor resistência mecânica $(3,4)$. Já foi observado que o módulo de elasticidade e a dureza nas áreas afetadas pela HMl encontram-se reduzidos em até $80 \%$ quando comparado ao esmalte sadio $(40,51)$.

Apesar da etiologia da HMI não estar totalmente esclarecida, alguns fatores são descritos como possíveis causas da hipomineralização molar incisivo. Dentre 
esses destacam-se os fatores de natureza sistêmica, como algumas doenças próprias da infância que ocorreram nos primeiros três anos de vida, tais como catapora, febre alta, asma, pneumonia, infecções de ouvido, dor de garganta e alergias $(19,20,21,22,25,39)$. O uso de algumas drogas como amoxicilina e ciclosporina, durante a primeira infância têm sido associadas com HMI (19, $20,25,39,42)$, assim como parto prematuro e complicações durante o nascimento (20).

Em 2008, a Sociedade Européia de Odontopediatria (EAPD), considerou que a HMl é de origem multifatorial, incluindo além de fatores sistêmicos, componentes genéticos (39). Mesmo a causa da HMI permanecendo obscura, parece ser indiscutível a relação entre as más condições de saúde durante os três primeiros anos de vida e a ocorrência do problema (39). Dessa forma foi proposto que crianças com saúde geral precária nos primeiros quatro anos de vida devem ser consideradas de alto risco para o desenvolvimento da hipomineralização molarincisivo (49).

No que se refere à prevalência de $\mathrm{HMI}$, a média no mundo, segundo Fragelli et al (2014) (48), varia de 2,4 a 40\%. Com uma taxa de prevalência elevada e, extrapolando para o campo da saúde pública, esses defeitos devem possuir uma atenção destacada durante o atendimento odontológico. Populações afetadas por essas mudanças requerem, prioritariamente, tratamento preventivo com atendimento rápido e eficaz.

Com relação ao Brasil, existem poucos trabalhos publicados a respeito. Soviero et at (2009) (50) examinaram crianças de 7 a 13 anos no intuito de determinar a prevalência de opacidades demarcadas nos primeiros molares permanentes. Como resultado, verificaram que 40,2\% das crianças examinadas possuíam pelo menos um primeiro molar afetado. Jeremias et al (2013) (95) estudaram a prevalência e a gravidade da HMI e sua relação com cárie dental em uma população de escolares, de 6 a 12 anos, na cidade de Araraquara. A prevalência da HMI nessa população representou 12,3\%, sendo o tipo leve o mais encontrado. Ainda, foi observada uma associação estatisticamente significante entre cárie e HMI somente nos dentes permanentes. Hoffmann et al (2007) (35), em um estudo transversal, avaliaram uma amostra de crianças de 5 a 12 anos na cidade de Indaiatuba. A prevalência de DDE, não só HMI, foi entre 20 e 30\% para a dentição 
decídua (5 anos) e permanente (12 anos), respectivamente, sendo que as opacidades demarcadas foram as mais prevalentes.

\subsubsection{Diagnóstico da HMI}

O exame clínico para detecção de HMI deve ser realizado, segundo Weerheijm (2003) (12), com os dentes limpos (ausência de placa dentária), na idade de oito anos preferencialmente, pois nessa idade todos os primeiros molares e a maioria dos incisivos permanentes já irromperam.

De acordo com a EAPD (41), o diagnóstico da HMl deve ser seguir os seguintes passos:

1. Primeiros molares e incisivos permanentes devem ser examinados;

2. O exame deve ser realizado em dentes úmidos e limpos:

3. A melhor idade para exame é aos oito anos;

4. Cada dente deve ser registrado segundo a presença ou ausência de opacidades demarcadas, quebra de esmalte após erupção dentária, restaurações atípicas, falha na erupção de molares ou incisivos permanentes e extrações relacionadas com HMI.

$\mathrm{Na}$ presente investigação, o critério para registro da HMI se baseou nas recomendações da EAPD (41). Entretanto, como observado na Tabela 1, as classificações clínicas foram adaptadas, entre elas restauração atípica, que foi subdividida em satisfatória e não satisfatória. 
Tabela 1 - Critério para registro da HMI, seus códigos e classificação de acordo com a gravidade, adaptado por Dra.Rita de Cássia Loiola Cordeiro.

\begin{tabular}{ccc}
\hline Escore & Descrição & Gravidade \\
\hline $\mathbf{0}$ & Ausência de opacidade demarcada & ----- \\
$\mathbf{1}$ & Opacidade demarcada branco creme & Leve \\
$\mathbf{2}$ & Opacidade demarcada amarelo marrom & Leve \\
$\mathbf{3}$ & Fratura de esmalte sem exposição de dentina & Moderada \\
$\mathbf{4}$ & Fratura de esmalte com exposição de dentina & Moderada \\
$\mathbf{5}$ & Restauração atípica satisfatória & Severa \\
$\mathbf{6}$ & Restauração atípica não satisfatória & Severa \\
$\mathbf{7}$ & Extraído devido HMI & Severa \\
$\mathbf{8}$ & Extraído por outras razões & Severa \\
$\mathbf{9}$ & Não irrompido & ----- \\
$\mathbf{1 0}$ & Esfoliado & ----- \\
\hline
\end{tabular}

A gravidade e a extensão da alteração variam de acordo com o indivíduo, podendo atingir um ou todos os primeiros molares permanentes (7), podendo ainda ser classificada em $(4,19,55,56,57)$ :

- Leve - opacidade presente, sem perda de estrutura de esmalte, com sensibilidade ocasional a estímulos externos. Tamanho do defeito é de aproximadamente $2 \mathrm{~mm}$.

- Moderada - opacidade presente com pequena perda de esmalte. Tamanho do defeito é de aproximadamente $3,5 \mathrm{~mm}$.

- Grave - perda de esmalte dentário presente com necessidade restauradora/tratamento, restaurações atípicas, cárie e sensibilidade espontânea. Tamanho do defeito é maior ou igual a $4,5 \mathrm{~mm}$.

A título de explicação, restaurações atípicas são aquelas que possuem tamanhos e desenhos diferentes das tradicionais cavidades resultantes da atividade de cárie e com opacidades nas bordas entre o dente e a restauração (59).

Portadores de $\mathrm{HMI}$ apresentam uma variedade de problemas associados como cárie, dor e sensibilidade dentária (18). Além disso, a placa dentária acumulase com facilidade nas áreas de dentina que ficam expostas após a quebra de 
esmalte, dificultando a escovação e podendo mascarar a presença de uma cavidade. Dessa forma, é muito importante que o profissional esteja atento para identificar todas essas variáveis, uma vez que o diagnóstico da HMI pode tornar-se difícil quando apenas um dente está afetado já apresentando lesão de cárie associada.

\subsubsection{Diagnóstico Diferencial entre HMI, Hipoplasia, Amelogênese Imperfeita e Fluorose}

O diagnóstico diferencial dos diversos tipos de DDE é importante para se evitar erros de diagnóstico e, principalmente, de tratamento (39).

Clinicamente a hipoplasia é observada como alterações brancas no esmalte que pode estar parcialmente formado ou, em alguns casos, ausente. As alterações podem aparecer de forma simétrica ou de forma isolada. O limite entre estas e o esmalte sadio apresenta-se suave, liso, sem grandes demarcações. É um defeito quantitativo, ou seja, existe redução da espessura do esmalte $(54,72)$.

Já as lesões resultantes de HMI apresentam-se, clinicamente, bem demarcadas, de coloração branca a amarelo-acastanhada e assimétricas. O esmalte é poroso, sem espessura reduzida (defeito qualitativo). As bordas da lesão com esmalte sadio apresentam-se irregulares e é comum fratura do esmalte afetado póserupção deixando a dentina exposta $(54,72)$. É importante ressaltar que a perda quantitativa de estrutura dentária ocorre após a erupção do dente, e não antes como nas hipoplasias.

A amelogênese imperfeita já é uma alteração na formação do esmalte que pode afetar ambas as dentições e é transmitida geneticamente (47). Todos os dentes encontram-se afetados e pode ser detectado antes mesmo da erupção por meio do exame radiográfico (72). Um inquérito detalhado sobre o histórico familiar é essencial na diferenciação entre a amelogênese e outros tipos de DDE.

A fluorose dentária apresenta-se clinicamente como opacidades difusas podendo afetar todos os dentes, além de serem simétricas e bilaterais (2). O esmalte nas áreas afetadas mostra-se cárie-resistente $(2,72)$. A gravidade das alterações 
está diretamente associada à quantidade, frequência e duração de ingestão de flúor (73).

\subsubsection{Manejo Clínico da Hipomineralização Molar Incisivo}

O rápido desenvolvimento de cárie em dentes afetados por HMI foi observado na literatura $(6,11,39,72)$. Por esta razão, é indicado que crianças com HMI sejam submetidas a ações preventivas tão logo esses dentes irrompam na cavidade bucal (61), uma vez que o tratamento restaurador em dentes afetados é desafiador para o profissional. Além das alterações estruturais do dente afetado que limitam a escolha do melhor material, a escassez de evidência e protocolos disponíveis na literatura também limitam a resolução do problema.

Geralmente, dentes com HMI requerem tratamentos extensivos, o que pode gerar apreensão tanto para o profissional quanto para 0 paciente, devido à dificuldade de se restaurar e anestesiar adequadamente esses dentes $(8,25)$. Acredita-se que o esmalte poroso nas áreas afetadas facilite a penetração de bactérias na dentina subjacente, resultando em uma inflamação crônica da polpa, dificultando a efetividade do ato anestésico (62).

Estudos verificaram que crianças com $\mathrm{HMI}$ receberam mais tratamentos dentários que crianças não afetadas (8,20). Jalevik et al (2002) (29) mostrou que aos nove anos de idade, crianças afetadas por HMI foram submetidas a procedimentos odontológicos, nos seus primeiros molares permanentes, aproximadamente dez vezes mais que crianças sem $\mathrm{HMI}$ e que, a média de tratamento foi de duas vezes maior para cada dente.

A gravidade da HMl está correlacionada às necessidades de tratamento do dente afetado $(28,47,59)$. Alguns defeitos do tipo leve requerem somente terapia preventiva, podendo ser monitorados sem qualquer intervenção invasiva. Defeitos mais graves, como quebra em esmalte, podem ser indicativos da necessidade de tratamentos mais invasivos e visitas de retorno com maior frequência (21).

Crianças com HMI apresentam frequentes problemas de comportamento frente ao tratamento dentário, sendo comumente relatado medo e ansiedade $(29,72)$. Os problemas de comportamento podem estar relacionados a sucessivas 
intervenções e/ou consultas para o mesmo elemento dentário, dor, dificuldade de anestesia ou até mesmo tratamentos realizados sem a analgesia adequada $(29,72)$.

Adicionalmente, o esmalte altamente poroso, a baixa concentração de mineral e a alta concentração de matéria orgânica facilita a fratura das margens das restaurações $(59,72)$. Outro desafio refere-se à adesão deficiente que ocorre em dentes com HMI, muito em função da estrutura dentária alterada. O padrão de condicionamento ácido em dentes hipomineralizados é pobre, na qual se observa dificuldade de formação de tags e, por conseguinte, dificuldade na retenção da restauração adesiva $(29,47,54,72)$. As repetidas fraturas nas bordas de restaurações realizadas nesses dentes também dificultam a abordagem restauradora (25).

Weerheijm (2004) (49) cita alguns materiais adesivos como opção de tratamento para dentes afetados por HMI - resina composta e cimento de ionômero de vidro -, porém, destaca que as restaurações devem possuir suas margens em esmalte sadio, preferencialmente. Apresenta, também, como opções de tratamento as coroas de aço e restaurações fundidas. Em outros casos, a indicação de exodontia seguida de correção ortodôntica está indicada.

William et al (2006) (10) elaboraram seis passos para facilitar a abordagem e manejo dos dentes com HMI. São eles:

1. Identificação do risco - identificar a história médica da criança correlacionando com possíveis fatores etiológicos da $\mathrm{HMI}$. O risco de desenvolver HMl deve ser identificado antes mesmo da erupção do primeiro molar permanente, preferencialmente, e essa informação pode ser conseguido por meio da história médica da criança durante os seus três primeiros anos de vida.

2. Diagnóstico precoce - avaliação do risco de desenvolvimento da HMI por meio do raio $x$, se possível, e monitoramento frequente desse dente durante a fase de erupção.

3. Remineralização e dessensibilização - durante a erupção do dente, o esmalte hipomineralizado apresenta grande suscetibilidade à cárie e à erosão. Dessa forma, recomenda-se remineralização com a aplicação tópica de flúor, verniz fluoretado e uso de dentifrício fluoretado para dentes sensíveis e avaliação da dieta. As ações de remineralização e dessensibilização devem ser iniciadas tão logo o elemento dentário com defeito seja visível na cavidade bucal. 
4. Prevenção da cárie dentária e fratura do esmalte pós-erupção - reforço da higienização em casa, adequação da dieta visando a redução da cariogenicidade e erosão da mesma, além do uso de selantes de fóssulas e fissuras.

5. Restaurações e extrações dentárias - restaurações em resina composta com o uso de adesivos self-etching ou restaurações extracoronárias como coroas de aço, podem ser necessárias de acordo com a destruição do elemento dentário. O cimento de ionômero de vidro pode ser também considerado um agente restaurador. Abordagem ortodôntica pós-exodontia deve ser considerada.

6. Manutenção e monitoramento - realizado por meio do monitoramento das margens restauradoras e possibilidade do uso de coroas dentárias a longo prazo.

Lygidakis et al (2010) (19), por sua vez, selecionaram diversas abordagens de tratamento de acordo com a gravidade da HMI. Para os casos leves sugerem ações preventivas, selantes, restaurações adesivas, com resina composta e microabrasão dentária. Nos casos graves estão indicados, além das abordagens utilizadas nos casos leves, coroas metálicas pré-fabricadas, exodontia aliada à ortodontia e coroas unitárias (19). Já o tratamento restaurador dos incisivos permanentes acometidos por $\mathrm{HMI}$, frequentemente ocorre por questões estéticas. Nesses casos, a restauração em resina composta deve ser considerada como primeira opção (26).

De maneira geral, observa-se uma diversidade grande de possibilidades de tratamento para o mesmo problema $(14,19,24,25,27,28,72)$, porém, sem consenso a respeito de qual material ou técnica devam ser utilizados para um adequado e duradouro tratamento restaurador. Isso pode ser explicado pela falta de estudos clínicos que objetivaram avaliar, em longo prazo, a performance de diferentes protocolos.

As dificuldades enfrentadas no manejo restaurador de dentes afetados por HMI são constantemente discutidas $(19,24,25,27,28,72)$, sendo que a seleção do material restaurador e a quantidade de tecido a ser removido constituem os principais pontos de divergência entre os autores $(14,19,24,25,27,28,72)$. 
Basicamente, observam-se duas correntes quanto à quantidade de tecido a ser removido: remoção de todo o esmalte afetado (toda a opacidade) e remoção apenas da porção mais porosa da opacidade $(19,24,25,26,27,28,72)$.

Quando se remove todo o esmalte afetado, espera-se que a restauração apresente uma longevidade maior, afinal, as bordas das restaurações encontrar-seão em esmalte sadio, portanto, não poroso, facilitando a adesão do material ao dente. Em contrapartida, a remoção de todo o esmalte defeituoso fragiliza muito a estrutura dentária, além da dificuldade de se delimitar a extensão exata da opacidade (26). Já a segunda opção, na qual se remove apenas a porção mais porosa da opacidade, é uma abordagem bem mais conservadora, porém, que aumenta o risco de fratura no limite restauração/bordos $(25,26)$.

Quanto à escolha do material, esta dependerá da gravidade da HMI, idade do paciente, cooperação da criança e localização da opacidade $(19,25,26)$. Dentre os materiais restauradores diretos, o amálgama é o menos indicado para dentes afetados por HMI, devido à pobre retenção observada em cavidades atípicas, que são frequentes nesses casos $(25,26)$.

Os materiais adesivos são usualmente selecionados para restauração dos dentes acometidos por HMI. Nesse contexto, o CIV apresenta-se como um material em potencial, seja para restauração temporária de curto ou médio prazo, devido basicamente às suas propriedades físicas (26).

O CIV atua no processo de remineralização dentária, protege a estrutura dentária remanescente da formação de novas lesões de cárie e diminui a sensibilidade $(27,28)$, além de ser de fácil aplicação e liberar flúor. Ainda, o CIV é biocompatível com a estrutura dentária e possui coeficiente de expansão térmica similar ao do dente $(27,28)$. Entretanto, a baixa resistência mecânica desse material frente às forças mastigatórias e a deficiência estrutural do dente com HMI, podem resultar na redução da longevidade das restaurações ionoméricas (28), estando contraindicado seu uso em áreas de estresse mastigatório $(19,26)$ e impedindo sua indicação como restauração definitiva (26). Porém, a literatura é escassa sobre esse tópico, sendo necessários mais trabalhos que avaliem restaurações de CIV em dentes com $\mathrm{HMI}$ (28). Até que isso aconteça, restaurações com CIV são recomendadas como uma opção válida para o manejo do problema (24).

$\mathrm{Na}$ Europa e nos Estados Unidos o uso da coroa metálica pré-fabricada é bastante comum. Para alguns autores, seu uso é indicado nos casos de HMl de 
moderado a grave, nos quais se observa perda de cúspide $(25,26)$. São vantagens: controle da sensibilidade dentária, previne a deterioração em longo prazo do dente afetado, estabelece os contatos interproximais de forma correta mantendo as relações oclusais, não é sensível à técnica como a resina composta além de requerer pouco tempo para o preparo e instalação da coroa. Em contrapartida, caso não sejam instaladas corretamente, podem produzir mordida aberta e gengivite (25).

Tratamentos conservadores devem ser sempre recomendados principalmente para as crianças menores até que elas possam crescer e cooperar com tratamentos mais complexos, caso sejam indicados (28). Tratamentos invasivos como a completa remoção do esmalte defeituoso devem ser postergados sempre que possível, até que a criança tenha maturidade emocional suficiente para compreender e cooperar no atendimento daqueles casos mais complexos (28).

Especificamente para este estudo, tendo em vista que a população alvo possui acesso restrito aos serviços de saúde, e que um dos materiais recomendados no tratamento de molares afetados por HMI é o CIV (26), o ART foi selecionado como protocolo restaurador a ser testado.

\subsection{TRATAMENTO RESTAURADOR ATRAUMÁTICO}

O ART foi criado na Tanzânia na década de 80 em resposta à dificuldade de se tratar pacientes locais de forma convencional. É aceito pela Organização Mundial de Saúde (OMS) como um procedimento que se baseia nos conceitos de mínima intervenção aplicável em nível de saúde pública. A Organização Panamericana de Saúde (OPAS) também o recomenda nos protocolos de atenção dos Ministérios da Saúde da região latino-americana (69).

É definido como uma abordagem minimamente invasiva que compreende medidas preventivas em relação à cárie dental e o controle da doença (65). É realizado com o uso exclusivo de instrumentos manuais, seguido de restauração com CIV de alta viscosidade. Está indicado para crianças muito jovens, pacientes ansiosos e com medo de dentista, pacientes com necessidades especiais, e para indivíduos com alta atividade de cárie $(69,71)$. A possibilidade de poder ser aplicado 
em ambiente escolar, ser de baixo custo operacional (15) e requerer em menor frequência o uso da anestesia, amplia o espectro de indivíduos que podem se beneficiar do tratamento, incluindo crianças e/ou pacientes que não conseguem pronto atendimento no serviço público.

O CIV quimicamente ativado é o material utilizado em associação ao ART e tem sido preconizado devido às suas propriedades físicas satisfatórias como: capacidade de aderir à estrutura dentária, liberar e se recarregar com flúor, prevenir e/ou paralisar a progressão da cárie, além de possuir módulo de elasticidade semelhante ao da dentina. Possui, ainda, biocompatibilidade com a polpa dentária e apresenta boa estabilidade de cor (65).

Os cimentos convencionais quimicamente ativados apresentam algumas limitações mecânicas e clínicas quando comparados aos de alta viscosidade, tais como o tempo de reação de geleificação prolongado, maior perda e/o ou incorporação de água nos minutos inicias de presa, baixa resistência à tração e compressão e problemas estéticos devido à sua translucidez limitada (99).

Em comparação aos CIVs quimicamente ativados, os CIVs de alta viscosidade contêm partículas de carga com dimensões menores e ácido liofilizado agregado ao pó, o que Ihes confere maior dureza superficial (97). No entanto, ainda apresentam porosidades e resistência mecânica inferior à do amálgama e da resina composta (65).

Mais recentemente, foi lançado no mercado um CIV classificado como de alta viscosidade, encapsulado e quimicamente ativado denominado Equia Forte® (GC America). Segundo o fabricante, o Equia Forte® é um CIV que adere igualmente ao esmalte e à dentina, independente da idade do dente, podendo ser utilizado em cavidades profundas. Após a restauração realizada, se aplica um selante de superfície (Equia Coat®, GC America), fotopolimerizável, que, segundo o fabricante, potencializa as propriedades físicas do material ao diminuir o desgaste superficial, além de deixá-la mais lisa (100).

Sabe-se, ainda, que os CIVs encapsulados apresentam maior liberação de flúor que os cimentos proporcionados manualmente, apresentam uma mistura final mais homogênea, menor microinfiltração marginal e é de fácil manipulação (97). Os cimentos disponíveis em frascos e manipulados manualmente estão mais sujeitos a erros no dimensionamento da proporção pó/líquido, a ponto de comprometer as propriedades físicas do material e, consequentemente, seu desempenho clínico. As 
alterações dimensionais durante a presa dos CIVs encapsulados são menores que as alterações dos fornecidos em frascos. De maneira geral, tem-se atribuído uma melhora nas propriedades dos CIVs encapsulados quando comparados aos cimentos disponíveis em frascos, no que se refere à liberação de flúor, tempo de presa, microinfiltração, presença de porosidades, resistência compressiva e resistência à tração $(97,101)$.

Quanto à taxa de sobrevida das restaurações de CIVs de alta viscosidade, estas quando comparada às restaurações de amálgama mostraram-se ígualmente efetivas num período de mais de seis anos de acompanhamento (98). De Amorim et al (2014) (75) também obtiveram taxas de sobrevida similares entre restaurações de amálgama e CIV de alta viscosidade (1 face e múltiplas faces) em dentes decíduos durante dois anos de acompanhamento.

Outros estudos comparam a taxa de sobrevida de restaurações ART classe I e classe II com resina e amálgama $(75,76,77)$. No caso de restaurações classe I, observou-se não haver diferença estatística entre restaurações ART, de resina ou de amálgama para dentes decíduos $(69,76,77)$. Para restaurações classe II ART, resultados semelhantes também foram reportados quando estas foram comparadas às restaurações de resina composta (76), porém, existe a necessidade de mais trabalhos para a confirmação desses achados.

Quanto ao uso dos CIVs de alta viscosidade em dentes permanentes, um estudo recente no qual o sistema Equia Filß (GC America), foi empregado e comparado à resina composta em pré-molares e molares permanentes, mostrou performance semelhante dos materiais após quatro anos de acompanhamento, tanto para classe I quanto classe II. Este estudo é um dos poucos que testaram os CIVs de alta viscosidade em dentes permanentes, mostrando um nicho potencial de aplicação desse material. Porém, mais estudos são necessários para que se possa obter maior evidência.

Outra vantagem indiscutível dos CIVs de alta viscosidade é a possibilidade de utilização do material em situações de campo por meio da técnica do ART. Esta técnica consiste, resumidamente, em remover a dentina desmineralizada e amolecida por meio da escavação com instrumentos manuais afiados e, na sequência, restaurar a cavidade com CIV de alta viscosidade (15,69). Após a remoção do tecido cariado, deve-se limpar a cavidade, a superfície oclusal e as fissuras adjacentes com ácido poliacrílico (10 a 40\%) embebido em bolinha de 
algodão, deixando atuar de 10 a 15 segundos, que deve ser removido logo em seguida utilizando-se bolinhas de algodão molhadas. O CIV deverá ser manipulado de acordo com as instruções do fabricante e, imediatamente inserido na cavidade. $O$ dedo indicador enluvado e vaselinado deverá pressionar o material por 40 segundos. Em seguida removem-se os excessos, checa-se a oclusão e faz-se a proteção da superfície. Recomendação para que o paciente não se alimente pelo menos na primeira hora é importante para melhores resultados (69). 


\section{OBJETIVOS}

\subsection{OBJETIVO GERAL}

- Avaliar a sobrevida de restauração ART realizadas em primeiros molares afetados por HMI em um grupo de escolares após seis e 12 meses de acompanhamento.

\subsection{OBJETIVOS ESPECÍFICOS}

- Determinar as necessidades de tratamento de crianças portadoras de HMI;

- Caracterizar as cavidades presentes em molares afetados por HMI;

- Testar o sucesso/longevidade de restauração ART em primeiros molares hipomineralizados (HMI), usando critério ART de avaliação;

- Determinar o perfil sócio-econômico das crianças que compuseram a amostra. 


\section{MATERIAL E MÉTODOS}

\subsection{ASPECTOS ÉTICOS}

Este estudo foi autorizado pela Secretaria de Educação do DF e aprovado pelo Comitê de Ética da Faculdade de Ciências da Saúde da Universidade de Brasília (sob o número CAAE - 31973413.0.0000.0030) (Anexo A).

Os tratamentos ocorreram após os pais e crianças terem assinado os termos de Consentimento Livre e Esclarecido (Anexo B) e de Assentimento (Anexo C), respectivamente.

\subsection{DESENHO CLÍNICO E SELEÇÃO DA AMOSTRA}

Em 2013 foi realizado um estudo de prevalência em escolas públicas do Paranoá-DF, fruto de um estudo de doutorado, ainda não finalizado, de Maria José da Silva Figueiredo Sé. Esse estudo envolveu crianças de ambos os sexos, na faixa etária compreendida entre seis e 11 anos. Do total de 1971 crianças examinadas, 184 foram diagnosticadas como portadoras de HMI.

Realizou-se, então, um levantamento inicial sobre a necessidade de tratamento por elas apresentada. Aquelas com necessidade de tratamento restaurador nos primeiros molares afetados foram incluídas no ensaio clínico. Foram excluídos os casos com indicação de endodontia e/ou extração dentária. Tais crianças receberam tratamento no Hospital Regional do Paranoá. As necessidades restauradoras na dentição decídua foram tratadas na própria escola, mas não fazem parte desta investigação.

Para se determinar a necessidade de tratamento, um examinador treinado e calibrado realizou os exames clínicos na própria escola, em macas portáteis com auxílio de sonda, espelho e iluminação artificial. Para o registro da cárie dentária foi utilizado o critério Nyvad (67) (Tabela 2) e para o diagnóstico da HMI, o critério da EAPD (41) adaptado pela Dra Rita de Cássia Loiola Cordeiro (Tabela 1). 
Radiografias não foram utilizadas como complemento ao exame clínico. A necessidade de tratamento foi caracterizada como se segue:

1) Sem necessidade de tratamento restaurador

2) Com necessidade de tratamento restaurador

3) Com necessidade de tratamento endodôntico

4) Com necessidade de exodontia 
Tabela 2 - Critério Nyvad (67) com seus códigos e descritores

\begin{tabular}{|c|c|c|}
\hline Característica & Código & Descrição \\
\hline HÍGIDO & 0 & $\begin{array}{l}\text { Esmalte com translucidez e textura normal (coloração } \\
\text { em fissuras permitidas, desde que hígida). }\end{array}$ \\
\hline $\begin{array}{c}\text { CÁRIE ATIVA } \\
\text { (superfície intacta) }\end{array}$ & 1 & $\begin{array}{l}\text { Superfície de esmalte branca ou amarelada com perda } \\
\text { de brilho e rugosa ao toque com ponta da sonda; } \\
\text { Superfície lisa: lesões de cárie típicas localizadas } \\
\text { próximas à margem gengival. } \\
\text { Fissura/fóssulas: morfologia intacta; lesão estendendo } \\
\text { ao longo das paredes da fissura. }\end{array}$ \\
\hline $\begin{array}{c}\text { CÁRIE ATIVA } \\
\text { (superfície irregular) }\end{array}$ & 2 & $\begin{array}{l}\text { Mesmo critério do código } 1 . \\
\text { Microcavidade restrita ao esmalte. }\end{array}$ \\
\hline $\begin{array}{l}\text { CÁRIE ATIVA } \\
\text { (cavitada) }\end{array}$ & 3 & $\begin{array}{l}\text { Cavidade facilmente visível a olho nu em } \\
\text { esmalte/dentina; superfície da cavidade amolecida a } \\
\text { sondagem leve. Pode haver ou não envolvimento } \\
\text { pulpar. }\end{array}$ \\
\hline $\begin{array}{l}\text { CÁRIE INATIVA } \\
\text { (superfície intacta) }\end{array}$ & 4 & $\begin{array}{l}\text { Superfície do esmalte está esbranquiçada, amarronzada } \\
\text { ou negra. Esmalte pode estar brilhante, duro e liso ao } \\
\text { suave toque da sonda através da superfície. Nenhuma } \\
\text { perda detectável clinicamente de substância. } \\
\text { Superfície lisa: lesão de cárie tipicamente localizada a } \\
\text { certa distância da margem gengival. } \\
\text { Fissura/fóssula: morfologia intacta, lesão estendendo ao } \\
\text { longo das paredes da fissura. }\end{array}$ \\
\hline $\begin{array}{l}\text { CÁRIE INATIVA } \\
\text { (superfície irregular) }\end{array}$ & 5 & $\begin{array}{l}\text { Mesmo critério do código } 4 \text {. Defeito superficial localizado } \\
\text { (microcavidade) restrita ao esmalte. }\end{array}$ \\
\hline $\begin{array}{l}\text { CÁRIE INATIVA } \\
\text { (cavitada) }\end{array}$ & 6 & $\begin{array}{l}\text { Cavidade facilmente visível a olho nu em } \\
\text { esmalte/dentina; superfície da cavidade pode estar } \\
\text { brilhante e dura à sondagem. Sem envolvimento pulpar. }\end{array}$ \\
\hline $\begin{array}{l}\text { RESTAURAÇÃO } \\
\text { (superfície hígida) }\end{array}$ & 7 & \\
\hline $\begin{array}{l}\text { RESTAURAÇÃO + } \\
\text { CÁRIE ATIVA }\end{array}$ & 8 & Lesão de cárie pode estar cavitada ou não. \\
\hline $\begin{array}{l}\text { RESTAURAÇÃO + CÁRIE } \\
\text { INATIVA }\end{array}$ & 9 & Lesão de cárie pode estar cavitada ou não. \\
\hline
\end{tabular}

Para a presente investigação, foram selecionados os dentes que apresentavam os códigos Nyvad 3, 5, 6, 8, 9. 
Dessa forma, das 184 crianças diagnosticadas com HMI, 60 crianças apresentavam as condições para serem incluídas no estudo clínico.

Os pais ou responsáveis das crianças responderam a um questionário sobre dados sócio-econômicos (Anexo D), por meio de contato telefônico. Os pais foram também questionados se sabiam que seus filhos tinham cárie. Caso a resposta fosse positiva, se tinham feito alguma tentativa de tratamento.

\subsection{ENSAIO CLÍNICO}

Todo o tratamento restaurador foi realizado na escola, com a criança deitada numa maca portátil por uma única dentista assistida por uma auxiliar. Previamente ao início da implementação dos tratamentos, tanto a operadora quanto a assistente foram treinadas quanto à realização das restaurações seguindo o protocolo do ART $(66,68)$.

Inicialmente o tecido cariado foi removido utilizando-se curetas afiadas (Kit ART, Duflex® - Rio de Janeiro). Caso houvesse queixa da criança, anestesia local foi administrada. Uma vez que a cavidade fosse considerada pronta para receber a restauração, esta foi classificada em: simples quando apresentava uma face envolvida, composta, com envolvimento de duas faces e complexa quando apresentava três faces envolvidas. Foram também catalogadas seguindo a classificação de Mount \& Hume Modificada (64):

- Estagio 0 - atividade de cárie sem cavitação

- Estágio 1 - cavidade pequena em esmalte

- Estágio 2 - cavitação em dentina sem enfraquecimento de cúspides

- Estágio 3 - extensa cavitação em dentina com enfraquecimento de cúspides

- Estágio 4 - cavitação muito extensa com destruição de uma ou mais cúspides

$\mathrm{Na}$ sequência, a cavidade foi condicionada utilizando-se o Cavity Conditioner® (GC America) durante 10 segundos. Após lavagem da cavidade usando bolinhas de algodão embebidas em água, foi realizado isolamento relativo com roletes de algodão e secagem da cavidade também utilizando bolinhas de 
algodão. Enquanto a operadora mantinha o ambiente seco, a auxiliar iniciava a ativação do ionômero Equia Forte® (GC America) encapsulado no misturador indicado pelo fabricante. Após o tempo de mistura, a cápsula contendo o CIV pronto para uso foi encaixado em pistola própria para esse sistema e inserido na cavidade limpa. Após o preenchimento da cavidade com o material, o operador executou pressão digital com o dedo enluvado e vaselinado no dente a ser restaurado por 40 segundos. Em seguida, fez-se a remoção dos excessos e checagem da oclusão com o uso do papel carbono fino. Limpou-se com bolinhas de algodão seca e, finalizou-se o procedimento com a aplicação de um selante de superfície resinoso e fotoativado (Equia Coat ${ }^{\circledR}$, GC America) por 20 segundos.

\subsection{ACOMPANHAMENTO LONGITUDINAL}

Para a avaliação do sucesso clínico das restaurações, um examinador calibrado e independente avaliou as mesmas num intervalo de seis e 12 meses, utilizando-se o critério ART modificado (Tabela 3) (84).

Tabela 3 - Critério ART Modificado seus códigos e a definição de sucesso e falha

\begin{tabular}{ccc}
\hline Código & Descrição & Definição \\
\hline $\mathbf{1}$ & Restauração presente e correta. & Sucesso \\
$\mathbf{2}$ & Pequeno defeito marginal e/ou desgaste com menos de 0,5 mm; & Sucesso \\
& sem necessidade de reparo. & \\
$\mathbf{3}$ & Defeito marginal superior a $0,5 \mathrm{~mm}$. Necessidade de reparo. & Falha \\
$\mathbf{4}$ & Desgaste superior a 0,5mm. Necessidade de reparo. & Falha \\
$\mathbf{5}$ & Presença de cárie na interface da restauração. Necessidade de & Falha \\
& reparo. & \\
$\mathbf{6}$ & Fratura da restauração e/ou dente. Necessidade de reparo. & Falha \\
$\mathbf{7}$ & Restauração ausente (perda completa). \\
$\mathbf{8}$ & Restauração ausente, outro tratamento foi realizado. & Falha \\
$\mathbf{1 0}$ & Dente ausente devido à extração. & Excluído \\
\hline
\end{tabular}




\subsection{ANÁLISE ESTATÍSTICA}

Os dados coletados foram analisados e codificados utilizando-se o software Stata Versão 14.1. As taxas de sucesso foram calculadas considerando as seguintes variáveis: número de superfícies envolvidas na restauração, extensão das cavidades, dente, sexo, idade da criança, gravidade da HMI e uso de anestesia local por meio dos testes ANOVA Qui-quadrado com nível de significância de 0,05. Ainda, as mesmas variáveis foram inseridas para obtenção de um modelo de regressão logística multivariado. 


\section{RESULTADOS}

\subsection{NECESSIDADE DE TRATAMENTO}

Todos os primeiros molares e incisivos permanentes das 184 crianças diagnosticadas com HMI durante o levantamento epidemiológico foram avaliados quanto à necessidade de tratamento, perfazendo um total de 2200 dentes (740 molares e 1480 incisivos). Detectou-se características de HMI em 447 molares e 158 incisivos $(27,5 \%)$ dos quais, $82,65 \%$ foram classificados sem necessidade de tratamento. Daqueles que necessitavam de tratamento (105 molares e um incisivo), $5,66 \%$ dos dentes $(n=6)$ apresentaram indicação de exodontia, 7,54\% $(n=8)$ de endodontia e em $86,80 \%(n=92)$ de restauração.

Das 60 crianças inicialmente diagnosticadas com necessidade restauradora $(n=92)$, verificou-se que após 4 meses do levantamento epidemiológico, 15 delas $(\mathrm{n}=16)$ não foram identificadas para o início do tratamento pois haviam se mudado do Paranoá sem deixar contato telefônico nos registros da Secretaria de Educação do DF. Totalizou-se, portanto, 45 crianças com 76 dentes para tratamento restaurador. No momento do atendimento verificou-se, ainda, que 1 criança $(n=1)$ já havia restaurado o dente selecionado para tratamento no Hospital Universitário de Brasília (HUB) e 15 dentes já apresentaram destruição avançada, sendo indicados para endodontia ou exodontia. Os dentes indicados para endodontia/exodontia foram eliminados do estudo. Ao final, o número de crianças que receberam tratamento foi 44 perfazendo um total de 60 dentes restaurados.

A cárie dentária foi diagnosticada em todos os dentes juntamente com sua necessidade de tratamento. 
O número de dentes tratados e as perdas amostrais estão apresentados na Figura 2.

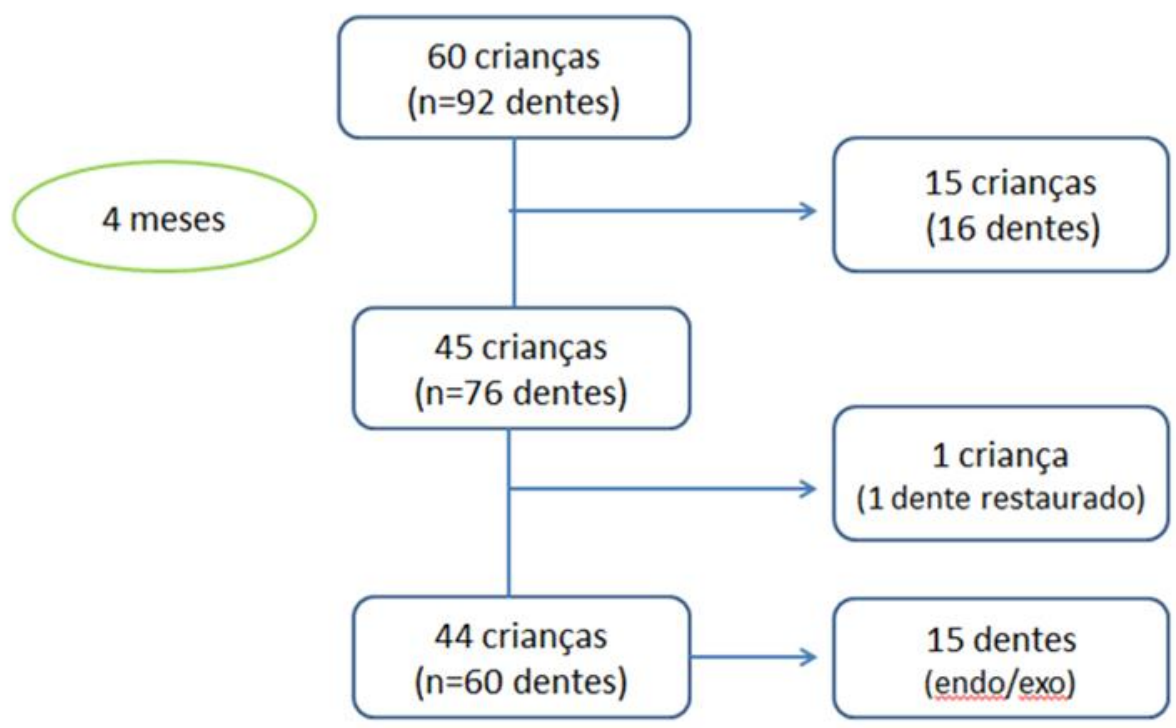

Figura 2: Fluxograma com o número de crianças/dentes elegíveis e os que compuseram a amostra do estudo.

\subsection{ANÁLISE DESCRITIVA DA AMOSTRA}

Fizeram parte do estudo 44 crianças. Destas, 24 (54,54\%) eram do sexo feminino e $20(45,45 \%)$ do sexo masculino. A média de idade foi de aproximadamente 10,5 ( $\pm 1,25)$ anos. As crianças foram tratadas em 10 escolas da região do Paranoá-DF. A distribuição de crianças por escola está apresentada na figura 3. 


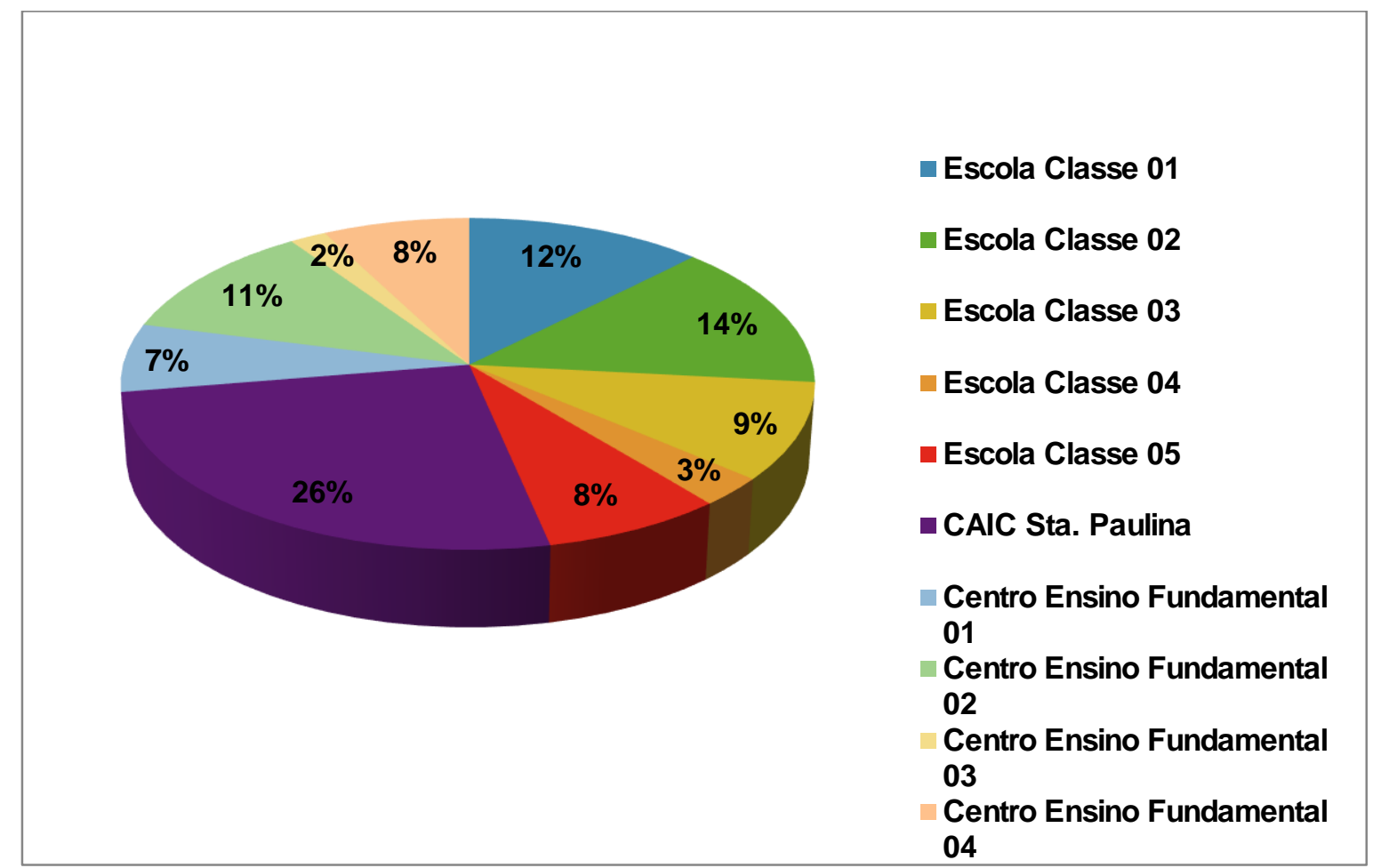

Figura 3 - Porcentagem de crianças atendidas de acordo com a escola

\subsubsection{Caracterização das lesões}

Foram restaurados 60 dentes, sendo 31 molares superiores $(51,67 \%) ; 28$ molares inferiores $(46,67 \%)$ e um incisivo central inferior $(1,67 \%)$.

Em relação à classificação da $\mathrm{HMI}$, todos os dentes foram classificados como grave, sendo que 57 dentes (95\%) apresentavam fratura de esmalte com exposição de dentina e três dentes (5\%) com restauração atípica não satisfatória.

Considerando a classificação em número de faces, 29 (48,3\%) envolveram apenas uma face; 20 (33,3\%) com envolvimento de duas faces e 11 (18,4\%) com três ou mais faces. Ao considerar a extensão das lesões, 25 (41\%) apresentavam lesão em dentina sem enfraquecimento de cúspide, 23 (37,7\%) com lesão em dentina e enfraquecimento de cúspide, e 13 (21,3\%) com lesões em dentina com destruição de uma ou mais cúspides. 


\subsubsection{Procedimento Restaurador}

Tanto a presença de dor como necessidade de anestesia previamente ao inicio do tratamento foram registradas. Nove crianças relataram dor provocada (15\%), porém, apenas quatro necessitaram de anestesia local. Não foram observadas associações significativas entre tamanho da cavidade e dor; e entre tamanho da cavidade e uso de anestesia $(p>0,05)$.

\subsubsection{Falhas Das Restaurações}

No período de 0-6 meses de avaliação, foi registrada uma falha, sendo classificada como 6 pelo critério ART modificado (Tabela 3) (84), o que caracteriza presença de fratura da restauração e/ou dente com necessidade de reparo. As demais restaurações foram classificadas com os códigos 1 (54 restaurações; 90\%) e 2 (cinco restaurações; 8,33\%), que significam estar em bom estado ou apresentar desgate marginal inferior a $0,5 \mathrm{~mm}$ sem necessidade de reparo, respectivamente.

No período de 6-12 meses de acompanhamento, não foi registrada nenhuma outra falha. Entretanto, quatro crianças (cinco restaurações) foram censuradas durante este intervalo de tempo por motivo de mudança de cidade e/ou escola. Nesse período, observou-se que 42 (74,78\%) restaurações permaneceram classificadas com código 1, e $12(22,22 \%)$ restaurações classificadas com código 2. Dessa forma, a probabilidade de um dente restaurado permanecer como sucesso não se alterou no período 0-6 e 6-12 meses, e foi de 98,3\%, como observado abaixo, na Tabela 4. 
Tabela 4 - Sobrevida das restaurações de ART nos períodos de 6 e 12 meses

\begin{tabular}{|c|c|c|c|c|c|c|}
\hline $\begin{array}{l}\text { Intervalo } \\
\text { (meses) }\end{array}$ & $\begin{array}{c}\text { Restaurações } \\
\text { avaliadas no } \\
\text { período }\end{array}$ & $\begin{array}{c}\text { Restaurações } \\
\text { censuradas }\end{array}$ & $\begin{array}{c}\text { Restaurações } \\
\text { em risco } \\
\text { durante o } \\
\text { período }\end{array}$ & $\begin{array}{c}\text { Falhas } \\
\text { durante o } \\
\text { intervalo }\end{array}$ & $\begin{array}{c}\text { Taxa de } \\
\text { sobrevida } \\
\text { durante o } \\
\text { intervalo }\end{array}$ & $\begin{array}{c}\text { Taxa } \\
\text { cumulativa de } \\
\text { sobrevida até } \\
\text { o fim do } \\
\text { período de } \\
\text { observação }\end{array}$ \\
\hline 6 & 60 & 0 & 60 & 1 & 0,983 & 0983 \\
\hline 12 & 54 & 5 & 54 & 0 & 1 & 0,983 \\
\hline
\end{tabular}

Uma análise bivariada utilizando a variável dependente "falha da restauração" e as variáveis independentes sexo, idade, dente, número de faces envolvidas (1, 2 ou mais faces), extensão (esmalte, dentina sem enfraquecimento de cúspide, dentina com enfraquecimento de cúspide e perda de cúspide) e dor foi realizada com intuito de verificar a associação entre essas variáveis. Somente a variável "número de faces envolvidas" apresentou associação significativa com a variável falha, uma vez que a restauração que falhou aos seis meses envolvia mais de três faces $(p=0,016)$. Todas as demais variáveis não apresentaram associação significativa com falha $(p>0,05)$.

$\mathrm{Na}$ proposição de um modelo de regressão logística, quando todas as variáveis foram incluídas (sexo, idade, dente, número de faces envolvidas, extensão e dor), o modelo não se apresentou significativo $(p=0,276)$ (Tabela 5$)$. 
Tabela 5 - Razão de chance e intervalo de confiança da sobrevida das restaurações de acordo com as diferentes variáveis independentes

\begin{tabular}{cccc}
\hline Falha & OR & Valor de $\mathbf{p}$ & 95\%IC \\
\hline Sexo &, 117 & 0,085 & $, 0101-1,34$ \\
Extensão & 1,31 & 0,774 & $, 206-8,35$ \\
$\begin{array}{c}\text { Número de } \\
\text { faces }\end{array}$ & 1,16 & 0,869 & $, 200-6,68$ \\
Idade & 0,91 & 0,816 & $, 419-1,98$ \\
Dente & 1,072 & 0,141 & $, 977-1,176$ \\
Dor & 2,72 & 0,484 & $, 163-45,43$ \\
\hline
\end{tabular}

\subsubsection{Questionário social pais/responsáveis}

A taxa de resposta ao questionário foi de $63,64 \%$. Os dados obtidos podem ser observados na Tabela 6 , indicando que a amostra foi composta por crianças que podem ser consideradas de vulnerabilidade social com base na renda familiar e nível de escolaridade do responsável.

Com relação à saúde bucal das crianças, menos da metade dos entrevistados informou ter consciência de que seu filho tinha cárie. Dos que disseram ter conhecimento, 53,57\% afirmaram que buscaram tratamento contra 46,42\% que não o fizeram. Dentre os que buscaram tratamento, 17,85\% procuraram atendimento privado, 3,47\% buscaram o Hospital Universitário de Brasília (HUB) e 32,14\% procuraram o Centro de Saúde. Daqueles que buscaram atendimento no centro de saúde, somente $44 \%$ foram avaliados (Tabela 6 ). 
Tabela 6 - Características das famílias incluídas no estudo considerando renda, nível de escolaridade e condições de vida

\begin{tabular}{|c|c|c|c|}
\hline Critério avaliado & $\begin{array}{l}\text { Critério } \\
\text { avaliado }\end{array}$ & $\mathbf{n}$ & Freqüência (\%) \\
\hline & Doméstica & 6 & $21,42 \%$ \\
\hline & $\begin{array}{c}\text { Auxiliar de } \\
\text { limpeza }\end{array}$ & 6 & $21,42 \%$ \\
\hline & Aposentado & 3 & $10,71 \%$ \\
\hline & Auxiliar & 3 & $10,71 \%$ \\
\hline \multirow[t]{8}{*}{ Profissão } & administrativo & & \\
\hline & Estoquista & 3 & $10,71 \%$ \\
\hline & Autônomo & 2 & $7,14 \%$ \\
\hline & Vigilante & 1 & $3,57 \%$ \\
\hline & Treinador & 1 & $3,57 \%$ \\
\hline & Padeiro & 1 & $3,57 \%$ \\
\hline & 1 Salário & 4 & $14,28 \%$ \\
\hline & Mínimo (SM) & & \\
\hline \multirow[t]{3}{*}{ Renda } & 1 a 2 SM & 16 & $57,14 \%$ \\
\hline & 2 a 5 SM & 8 & $28,57 \%$ \\
\hline & Própria & 19 & $67,85 \%$ \\
\hline \multirow[t]{3}{*}{ Moradia } & Alugada & 5 & $17,85 \%$ \\
\hline & Outros & 4 & $13,28 \%$ \\
\hline & Fundamental & 15 & $53,57 \%$ \\
\hline \multirow[t]{3}{*}{ Escolaridade } & Médio & 12 & $42,85 \%$ \\
\hline & Superior & 3 & $1,07 \%$ \\
\hline & Incompleto & & \\
\hline \multirow[t]{2}{*}{ Sabia que o filho tinha cárie? } & Sim & 12 & $42,85 \%$ \\
\hline & Não & 16 & $57,14 \%$ \\
\hline Procurou atendimento & Sim & 15 & $53,57 \%$ \\
\hline \multirow[t]{2}{*}{ odontológico? } & Não & 13 & $46,42 \%$ \\
\hline & Particular & 5 & $17,85 \%$ \\
\hline Onde procurou atendimento & HUB & 1 & $3,47 \%$ \\
\hline \multirow[t]{2}{*}{ odontológico? } & Centro de & 9 & $32,14 \%$ \\
\hline & Saúde & & \\
\hline Foi atendido no Centro de & Sim & 4 & $44 \%$ \\
\hline Saúde? & Não & 5 & $55 \%$ \\
\hline
\end{tabular}




\section{DISCUSSÃO}

Este estudo teve como objetivo avaliar a sobrevida de restaurações ART realizadas em primeiros molares afetados por $\mathrm{HMI}$ em um grupo de escolares do DF. Os resultados mostraram alta taxa de sucesso após 12 meses, e que o protocolo ART realizado em ambiente escolar pode ser uma opção factível de manejo do problema. Porém, o nível de evidência desses resultados pode ser questionado, uma vez não ter havido a inclusão de grupo controle, o que pode ser considerada uma limitação do estudo. Entretanto, a escolha do desenho metodológico baseou-se em dois critérios: não haver um protocolo de consenso no que se refere ao tratamento de dentes com $\operatorname{HMl}(14,19,24,25,27,28,72)$, o que indicaria o melhor material/técnica para ser usado como controle; e o fato de, após o estudo epidemiológico, a maioria dos pais terem se negado a comparecer ao Hospital Universitário de Brasília, que fica cerca de $30 \mathrm{~km}$ do Paranoá, para que seus filhos recebessem gratuitamente o tratamento. De acordo com o relato dos pais, a distância e a inexistência de alguém que pudesse levar seus filhos para 0 atendimento eram as principais razões para tal conduta. Assim, optou-se por testar uma abordagem que pudesse ampliar o acesso das crianças ao tratamento, neste caso o ART, considerando que dentes afetados por HMI com fratura pós-eruptiva associadas à cárie ou com restaurações apresentando falhas, se não tratados a tempo, muito provavelmente, serão perdidos num futuro próximo.

Outro ponto metodológico importante a ser discutido refere-se à seleção da amostra. Para que se possa delinear um ensaio clínico randomizado, é essencial que os grupos de comparação sejam similares, exceto no quesito terapia a ser testada (88). Em função das características particulares da HMI (porosidade do esmalte e localização das opacidades), sabe-se que as cavidades surgirão nos locais de quebra pós-eruptiva do esmalte $(8,21,31)$, gerando cavidades atípicas, diferente daquelas que se desenvolvem exclusivamente em função da presença de cárie. Dessa forma, infere-se que a randomização de dentes baseada no tamanho/extensão da cavidade seria uma meta difícil de ser alcançada.

Assim, para que fosse possível tratar num intervalo de tempo curto várias crianças com HMI, a seleção foi feita a partir de um estudo epidemiológico representativo da população do Paranoá - DF que foi finalizado em novembro de 
2013. O estudo identificou 184 crianças portadoras de HMI, cuja necessidade restauradora foi observada em 60 delas. Porém, a implementação da presente investigação só ocorreu 4 meses depois, após o retorno das crianças das férias escolares de verão, o que reduziu o número amostral para 45 crianças, uma vez que 15 delas havia mudado de cidade. Destas, que inicialmente apresentavam 76 dentes com HMI com indicação de restauração, só foi possível tratar 60 dentes, já que 15 dentes foram julgados, no momento da intervenção, como necessitando de endodontia/exodontia, e uma criança com um único dente afetado havia recebido tratamento no HUB. Tais resultados são suportados pela literatura e evidenciam a necessidade de diagnóstico precoce para a HMl e, quando já são observadas necessidades restauradoras, que os tratamentos sejam realizados o mais breve possível $(24,26,30,39,54,61,72)$.

Neste estudo, notou-se que em um intervalo de tempo curto, dentes que poderiam ter sido restaurados progrediram para estágios mais avançados, como já observado na literatura $(8,24,26,27)$, requerendo terapias de maior grau de complexidade e custo, o que poderia dificultar ainda mais a resolução do problema. Isso porque, a caracterização sócio-econômica das crianças da amostra estudada evidenciou que a grande maioria é proveniente de famílias cuja renda não ultrapassa a dois salários-mínimos $(71,42 \%)$ e que o nível de escolaridade do responsável, em mais da metade dos casos (53,57\%), não foi superior ao nível fundamental. Estes são dados importantes, uma vez que tanto a renda familiar quanto o nível de escolaridade dos pais estão relacionados com as condições de saúde bucal de seus filhos. Quanto mais baixa a renda e menor o nível de instrução, pior é a condição de saúde bucal $(89,90,91)$.

Quanto à situação de vulnerabilidade social da população, apesar de não ter sido possível coletar informações de $100 \%$ das familias, acredita-se que essa seja a realidade da grande maioria das crianças incluidas na amostra. Dados oficiais indicam que o Paranoá apresenta um dos menores índices de desenvolvimento humano do Distrito Federal (81). Nesse contexto, a grande maioria dessas famílias depende do sistema público de saúde como forma de obter tratamento odontológico. Essa afirmação é referendada pelo número de dentes com necessidade de tratamento e pelo relato dos pais quanto à dificuldade de atendimento no serviço público. Isso parece ser recorrente, uma vez que outro estudo realizado na mesma 
região administrativa evidenciou, também, o baixo acesso dessa população aos serviços de saúde (92).

Dessa forma, acredita-se que a opção pelo protocolo ART realizado em campo foi, seguramente, a escolha mais acertada. Por meio dessa estratégia, foi possível, num período de apenas 20 dias, uma única operadora acompanhada por uma auxiliar, realizar todos os procedimentos. Vale ressaltar que os tratamentos foram realizados em 10 escolas diferentes do Paranoá. Sabe-se que o ART é uma abordagem que tem sido utilizada em outros países, ampliando o acesso da população aos serviços de saúde (102) e aumentando o número de procedimentos restauradores. Em um estudo realizado na África do Sul, observou-se que a introdução do ART no serviço público aumentou o número de dentes restaurados tanto para a dentição decícua quando para a dentição permanente (103). Adicionalmente, a baixa necessidade de anestesia na abordagem ART pode ser vista como mais uma vantagem oferecida pela técnica, principalmente, ao considerar como público alvo crianças que estão sendo atendidas desacompanhadas. O ART mostrou-se, especialmente, importante no manejo de comportamento quando o dentista não era especialista em odontopediatria (15), como ocorreu na presente investigação. Das 44 crianças tratadas, apenas quatro requereram anestesia local durante o procedimento. Este é um resultado relevante haja vista que as cavidades, na sua grande maioria, eram extensas com lesão de cárie associada. Acredita-se que a baixa necessidade de anestesia local relacionada ao ART é decorrente do uso de instrumentos manuais exclusivamente durante acesso e limpeza da cavidade, porém, é uma hipótese que merecer ser melhor investigada.

Quanto aos resultados referentes à sobrevida das restaurações, uma alta taxa de sucesso (98\%) foi obtida após 12 meses de acompanhamento. Este resultado foi superior àquele encontrado por Fragelli et al (2014) (28), que obteve 78\% de sucesso, também, em restaurações realizadas em dentes afetados por HMI. Em ambos os estudos, utilizou-se CIV de alta viscosidade. Entretanto a técnica restauradora e o tipo de CIV foram diferentes. Na presente investigação, as restaurações foram colocadas seguindo a técnica $A R T$, na qual não se utiliza isolamento absoluto e o CIV utilizado foi do tipo encapsulado, diferentemente do estudo de Fragelli et al (2014) (28). Quanto ao isolamento absoluto, uma revisão sistemática recente mostrou que a evidência de que restaurações realizadas sob isolamento absoluto sejam superiores àquelas realizadas sob isolamento relativo é 
de muito baixa qualidade (104). Com relação ao tipo de material, este é o primeiro estudo clínico que utilizou o Equia Forte® (GC America), não sendo possível comparar esses resultados com estudos similares. Porém, Gurgan et al (2015) (87) avaliaram a performance clínica do CIV Equia Fil@ (GC America) com protetor de superfície (Equia Coat ${ }^{\circledR}$, GC America) em pré-molares e molares permanentes, durante quatro anos em comparação à resina composta microhíbrida. Os autores mostraram que a performance clínica do CIV Equia Filß foi similar à da resina, tanto para cavidades classe I como para cavidades classe II (87). O fabricante relata que - Equia Forte® é uma versão aprimorada do Equia Filß, apresentando como diferencial o tamanho das partículas (100). Além disso, ambos os materiais (Equia Filß e Equia Forte®) recomendam que a proteção de superfície seja realizada com um selante resinoso desenvolvido especificamente para essa linha de produtos, 0 que parece melhorar a lisura final da restauração e diminuir o desgaste da superfície. Dessa forma, acredita-se que o material utilizado no presente estudo tenha tido uma influência nos resultados de sobrevida, considerando que Fragelli et al (2014) (28) utilizaram CIV manipulado manualmente sem informação quanto a proteção de superfície .

Ao se analisar os fatores que poderiam infuenciar no sucesso do tratamento, observou-se que a localização do dente (inferior ou superior), a idade da criança, sexo, dor provocada e extensão das cavidades não foram determinantes para caracterizar falha. Porém, o número de faces mostrou-se associado aos insucessos, já que a única falha ocorrida foi em dente com mais de três faces envolvidas. Assim, um resultado ruim para este dente já era esperado, uma vez que a colocação de ionômero de vidro em áreas de stress mastigatório não é recomendada $(19,87)$. Entretanto, o resultado para restaurações envolvendo duas superfícies foi bastante positivo e superior ao que normalmente é relatado na literatura para dentes decíduos $(15,69,76,106)$. Em relação aos dentes permanentes poucos estudos estão disponíveis. Em um estudo retrospectivo realizado no Reino Unido, em pacientes com idade média de 57 anos, no qual foram incluídas restaurações de CIV de alta viscosidade acompanhadas por no mínimo cinco anos, mostrou uma boa performance das restaurações ao se considerar preservação da anatomia (86\%) e integridade marginal (69\%) (105). Em outro trabalho nas quais restaurações classe II em dentes permanentes foram acompanhadas por quatro anos, observou-se taxa de falha de 7,7\% em restaurações inoméricas (87). Entretanto, há de se considerar que 
nos dois estudos mencionados acima, o CIV foi empregado em dentes cariados, diferentemente do que aconteceu na presente investigação, cujos dentes eram, também, afetados por HMI. Finalmente, ainda sobre as restaurações realizadas, é difícil discutir o sucesso obtido para a restauração em dente anterior, uma vez que apenas um incisivo inferior apresentou necessidade restauradora, o que já foi relatado na literatura $(4,10,18,26,41)$. De maneira geral, embora os resultados tenham sido bastante promissores, é precoce recomendar o CIV de alta viscosidade como material de escolha para áreas de esforço mastigatório, uma vez que o número de dentes tratados no presente estudo é derivado de uma amostra de conveniência. Dessa forma, mais estudos são necessários para confirmação dos resultados aqui obtidos.

Apesar disso, é possível propor o CIV como uma alternativa de tratamento da HMI para manutenção destes dentes funcionalmente em boca, até que possam ser restaurados definitivamente, como sugeriu Fragelli et al (2014) (28). Outras opções de manejo seriam as coroas de aço e a resina composta. Com relação às coroas de aço, muito utilizadas e indicadas nos Estados Unidos e Europa $(14,25)$, essas não foram consideradas nesse estudo, uma vez que não estão disponíveis no mercado nacional. No que se refere às resinas compostas, o esmalte altamente poroso, a baixa concentração de mineral e a alta taxa de matéria orgânica em dentes afetados por HMI contribui para uma adesão deficiente $(29,47)$. Tem-se observado que a formação de tags após o condidionamento ácido nesses dentes, que é um passo extremamente importante para a adesão da resina, é deficiente, o que reflete negativamente na retenção da restauração $(29,47,54,72)$. Apesar disso, pela falta de estudos e alternativas de manejo, a resina composta ainda tem sido sugerida como material restaurador para dentes com ateração de esmalte (49). Entretanto, para dentes com HMI, com o objetivo de melhorar a sobrevida das restaurações tem-se recomendado a remoção de toda a opacidade $(25,26)$. Esta é uma estratégia extremamente invasiva, principalmente, para aqueles casos nos quais toda a coroa do dente está afetada e a criança é bastante jovem.

Diante do que já foi exposto, é possível afirmar que o ART aplicado em campo mostrou-se efetivo na manutenção de dentes afetados por HMI. Importante também ressaltar, que em todas as visitas a criança foi orientada com relação a hábitos saudáveis de higiene e dieta, que é outra vertente inerente ao protocolo ART 
e que não foi abordada no presente estudo. Ainda, considerando tudo o que foi verificado nos dados do questionário a respeito das variáveis sócio-econômicas e dificuldade dessa população em ter acesso aos serviços de saúde, quer seja por razões financeiras (clínica privada) ou por longa espera (centro de saúde), perguntase: o que teria acontecido com todos esses molares caso o tratamento não tivesse sido ofertado na escola? Apesar de não ser possível responder com precisão essa pergunta, acredita-se que a grande maioria desses teria sido extraída, ressaltandose a necessidade de se desenvolver políticas públicas especialmente voltadas para o manejo da HMI. 


\section{CONCLUSÃO}

- A maioria dos dentes com HMI não apresentou necessidade de tratamento, e aqueles com necessidade de tratamento, requerem majoritariamente restaurações diretas.

- Dentes afetados por HMI apresentam cavidades atípicas, uma vez que foram associadas à quebra pós-eruptiva, não seguindo um padrão comum definido como ocorre para cárie dentária.

- As restaurações ART, colocadas em campo, para restauração em primeiros molares permanentes afetados por $\mathrm{HMI}$, mostraram-se eficazes para preservação da estrutura dentária desses dentes.

- Restaurações envolvendo três ou mais faces tiveram maior chance de falhar no período de 12 meses. 


\section{REFERÊNCIAS}

1. Weerheijm KL, Jalevik B, Alaluusua S. Molar incisor hypomineralization. Caries Res. 2001; 35:390-1.

2. Ghanim A, Elfrink M, Weerheijm K, Mariño R, Manton D. A practical method for use in epidemiological studies on enamel hypomineralisation. Eur Arch Paediatr Dent. 2015; 16(3):235-46

3. Jälevik B, Norén JG. Enamel hypomineralization of permanent first molars: a morphological study and survey of possible aetiological factors. Int J Paediatr Dent. 2000;10(4):278-89.

4. Jalevik B, Klingberg G, Barregard L, Nóren JG. The prevalence of demarcated opacities in permanent first molars in a group of Swedish children. Acta Odontol Scand. 2001;59(5):255-60.

5. Weerheijm KL. Molar Incisor Hypomileralisation (MIH). Eur J Paediatr Dent. 2003;4(3):114-20.

6. Weerheijm KL, Groen HJ, Beentjes VEVM, Poorterman JHG. Prevalence of cheese molars in eleven-year-old Dutch children. J Dent Child. 2001;68(4):259-62.

7. Jalevik B, Nóren JG, Klingberg G, Barregard L. Etiologic factors influencing the prevalence of demarcated opacities in permanent first molars in a group of Swedish Children. Eur J Oral Sci 2001; 109:230-234.

8. Lygidakis NA. Treatment modalities in children with teeth affected by molar-incisor enamel hypomineralisation (MIH): a systematic review. Eur Arch Paediatr Dent 2010; 65-74.

9. Chawla N, Messer LB, Silva M. Clinical Studies on Molar-incisorhypomineralisation. A systematic review. Eur Arch Paediatr Dent 2010; 10:53-58. 
10. William V, Messer LB, Burrow MF. Molar Incisor Hypomineralisation: review and recommendations for clinical management. Pediatr Dent 2006; 28:224-232.

11. Jälevik B, Klingberg GA. Dental treatment, dental fear and behaviour management problems in children with severe enamel hypomineralisation of their permanent first molars. Int J Paediatr Dent. 2002 Jan; 12 (1):24-32.

12. Willmott NS, Bryan RAE, Duggal MS. Molar-Incisor-Hypomineralisation: A Literature review. Eur Arch Paediatr Dent 2008 Dec; 9(4):172-179.

13. Soviero V. et al. Prevalence and distribution of demarcated opacities and their sequelae in permanent 1st molars and incisors in 7 to 13 year-old Brazilian children. Acta Odontol Scand. 2009; 67(3):170-175.

14. Koch MJ, García-Godoy F. The Clinical Performance of Laboratory-Fabricated Crowns Placed on First Permanent Molars whith Developmental Defects. JADA 2000 Sep; 131:1285-1290.

15. Frencken JE, Leal SC, Navarro MFL (2012) 25 years atraumatic restorative treatment (ART) approach: a comprehensive overview. Clin Oral Invest; epub in print. DOI 10.1007/s00784-012-0783-4

16. Frencken JE, Holmgren CJ. Atraumatic restorative treatment for dental caries. Nijmegen: STI Book B.V.;1999.

17. Wogelius $P$, Haubeck D, poulsen S. Prevalence and distribuition of demarcated opacities in permanent $1^{\text {st }}$ molars and incisors in 6 to 8 year old Dannish children. Acta Odontol Scand 2008, 66:58-64.

18. Garcia-Margarit M, Catalá-Pizarro M, Montiel-Company JM, Almerich-Silla JM. Epidemiologic study of molar-incisor hypomineralization in 8-year-old Spanish children.Int J Paediatr Dent. 2014 Jan;24(1):14-22. 
19. Lygidakis NA, Wong F, Vierrou AM, Alaluusua S, Espelid I. Best clinical practice guidance for clinicians dealing with children presenting with molar incisors hypomineralisation (MIH). An EADP Policy Document. Eur Arch Paediatr Dent 2010; $11: 75-81$.

20. Chawla N, Messer LB, Silva M. Clinical Studies on Molar Incisor Hypomineralisation Part 1: Distribution and Putative Associations. Eur Arch Paediatr Dent 2008 Dec; 9(4):180-190.

21. Chawla N, Messer LB, Silva M. Clinical Studies on Molar Incisor Hypomineralisation Part 2: Development of a Severity Index. Eur Arch Paediatr Dent 2008 Dec; 9(4):191-199.

22. Ford D, W-Kim S, Kazoullis S, Holcombe T, Newman B. A Controlled Study of Risk Factors for Enamel Hypoplasia in the Permanent Dentition. Pediatr Dent. 2009 Sep-Oct;31(5):382-8.

23. Jälevik B. Prevalence and Diagnosis of Molar-Incisor- Hypomineralisation (MIH): A systematic review. Eur Arch Paediatr Dent. 2010 Apr;11(2):59-64.

24. Takahashi, K, Correia, ASC, Cunha, RF. Molar incisor hypomineralization. The J Clin Pediat Dent 2009; 33(3): 193-198.

25. William V, Messer LB, Burrow MF. Molar Incisor Hypomineralisation: review and recommendations for clinical management. Pediatr Dent 2006; 28:224-232.

26. Fayle SA. Molar-incisor hypomineralisation: restorative management. Eur J Paediatr Dent 2003; 4:121-126.

27. De Oliveira DC, Favretto CO, Cunha, RF. Molar incisor hypomineralization: Considerations about treatment in a controlled longitudinal case. J Indian Soc Pedod Prev Dent 2015; 33: 152-5. 
28. Fragelli CMB, Souza JF, Jeremias F, Cordeiro RCL, Santos-Pinto L. Molar incisor hypomineralization $(\mathrm{MIH})$ : conservative treatment management to restore affected teeth. Braz Oral Res [online]. 2015;29(1):1-7

29. Jalevik B, Klingberg GA. Dental treatment, dental fear and behavior management problems in children with severe enamel hypomineralization of their first molars. Int $J$ Paed Dent. 2002;12:24-32.

30. Elfrink, MEC, Ten-Cate, JM, Jaddoe, VWV, Hofman, A, Moll, HA, Veerkamp, JSJ. Deciduous Molar Hypomineralization and Molar Incisor Hypomineralization. J Dent Res. 2012 Jun;91(6):551-5.

31. Kosma I, Kevrekidou A, Boka V, Arapostathis K, Kotsanos N. Molar incisor hypomineralisation $(\mathrm{MIH})$ : correlations with dental caries and dental fear. Eur Arch Paedriatr Dent 2016 Apr;17(2):123-9.

32. Costa-Silva CM, Jeremias F, de Souza JF, Cordeiro RCL, Santos-Pinto L, Zuanon ACC. Molar incisor hypomineralization: prevalence, severity and clinical consequences in Brazilian children. Int J Paediatr Dent. 2010 Nov;20(6):426-34.

33. Willmott NS, Bryan RAE, Duggal MS. Molar-Incisor-Hypomineralisation: A Literature review. Eur Arch Paediatr Dent 2008 Dec; 9(4):172-179.

34. Heitmüller D, Thiering $E$, Hoffmann U, Heinrich J, Manton D, Kühnisch J, Neumann C, Bauer CP, Heinrich-Weltzien R, Hickel R, GINIplus study group. Is there a positive relationship between molar incisor hypomineralisations and the presence of dental caries? Int J Paediatr Dent. 2013 Mar; 23(2): 116-24.

35. Hoffmann RH, De Sousa Mda L, Cypriano S. Prevalence of enamel defects and the relationship to dental caries in deciduous and permanent dentition in Indaiatuba, São Paulo, Brazil. Cad Saude Publica. 2007;23(2):435-44. 
36. Bayne SC, Scmalz G. Reprinting the classical article on USPHS evaluation methods for measuring the clinical research performance of restorative materials. Clin Oral Invest. 2005 Nov;9:209-214.

37. Lygidakis NA, Dimou G, Briseniou E. Molar-incisor-hypomineralisation (MIH). Retrospective clinical study in Greek children. I. Prevalence and defect characteristics. Eur Arch Paediatr Dent 2008; 9: 200-6.

38. Oliveira, Tereza Raquel Mourão de. Hipomineralização molar incisivo: etiologia e impacto na qualidade de vida dos escolares do Paranoá-DF. 2015. 71 f., il. Dissertação (Mestrado em Ciências da Saúde)—Universidade de Brasília, Brasília, 2015.

39. Condó R, Perugia C, Maturo P, Docimo R. MIH: Epidemiologic clinic study in paediatric patient. Oral \& Implantol. 2012 Anno V, n 2-3:58-69.

40. Farah RA, Monk BC, Swain MV, Drummond BK. Protein content of molar-incisor hypomineralisation enamel. J Dent. 2010 Jul; 38(7):591-6.

41. Weerheijm KL, Duggal M, Mejare I, Papagiannoulis L, Koch G, Martens LC, Hallonsten AL. Judgement criteria for molar incisor hypomineralization $(\mathrm{MIH})$ in epidemiologic studies: a summary of European meeting on $\mathrm{MIH}$ held in Athens, 2003. Eur J Paed Dent, 2003;3:110-3.

42. Laisi S, Sahlberg C, Arvio P, Lukinmaa PL, Alaluusua A. Amoxicillin may cause molar incisor Hypomineralization. J Dent Res 2009; 132-136.

43. Jälevik B, Klingberg G. Treatment outcomes and dental anxiety in 18-year-olds with $\mathrm{MIH}$, comparisons with healthy controls - a longitudinal study. Int $\mathrm{J}$ Paediatr Dent. 2012 Mar;22(2):85-9.

44. Gandhi S, Crawford P, Shellis P. The use of a 'bleach-etch-seal' deproteinization technique on MIH affected enamel. Int J Paediatr Dent. 2012 Nov;22(6):427-34. 
45. Neville BW, Damm DD, Allen JE, Bouquot JE. Anomalias dos dentes. In: Neville BW, Damm DD, Allen JE, Bouquot J, editor. Patologia oral e maxilofacial. Rio de Janeiro: Guanabara Koogan; 1998. p.43-92.

46. Mcdonald RE e Avery DR. Odontopediatria. Rio de Janeiro: Guanabara Koogan; 2000. p.83-97.

47. Marsillac MWS, Batista AMR, Oliveira J, Rocha MJC. Alterações na Amelogênese e suas Implicações Clínicas: Relatos de casos. Rev. Fac. Odontol. Porto Alegre, v. 50, n. 1, p. 9-15, jan./abr., 2009.

48. Lunardelli SE, Peres MA. Prevalence and distribuition of developmental enamel defects in the primary dentition of pre-school children. Braz Oral Res 2005; 19(2):144-9.

49. Weerheijm KL. Molar incisor hypomineralization (MIH): clinical presentation aetiology and management. Dental Update. 2004;31(1):9-12.

50. Soviero V, Haubek D, Trindade C, Da Matta T, Pousen S. Prevalence and distribuition of demarcated opacities and their sequelae in permanente 1st molars and incisors in 7 to 13-year-old Brazilian children. Acta Odontol Scand. 2009;67: 1705.

51. Mahoney E, Ismail FSM, Kilpatrick N, Swain M. Mechanical properties across hypomineralized/hypoplastic enamel of first permanent molar teeth. Eur J Oral Sci 2004; $112: 497$.

52. Jalëvik B, Klingberg G. Treatment outcomes and dental anxiety in 18-years-old with $\mathrm{MIH}$, comparisons with healthy controls - a longitudinal study. Int J Paediatr Dent. 2012;22:85-91.

53. Leppäniemi A, Lukinmaa PL, Alaluusua S. Non-fluoride hypomineralizations in the first molars and their impact on the treatment need. Caries Res. 2001;35:36-40. 
54. Márcia Pereira Alves dos Santos and Lucianne Cople Maia (2012). Molar Incisor Hypomineralization: Morphological, Aetiological, Epidemiological and Clinical Considerations, Contemporary Approach to Dental Caries, Dr. Ming-Yu Li (Ed.), InTech, DOI: 10.5772/37372. Available from: http://www.intechopen.com/books/contemporary-approach-to-dental-caries/molarincisor-hypomineralization-epidemiological-morphological-and-clinicalconsiderations-

55. Jalevik B. Prevalence and Diagnosis of Molar-Incisor-Hypomineralisation (MIH): A systematic review. Eur Archs Paediatr Dent. 2010;11:59-64.

56. Alaluusua S, Lukinamaa P-L, Koskimies M, et al. Development dental defects associated with long breast feeding. Eur J Oral Sci 1996b;104:439-497.

57. Calderara PC, Gerthoux PM, Mocarelli P, et al. The prevalence of molar incisor hypominerlisation $(\mathrm{MIH})$ in a group of italian school children. Eur $\mathrm{J}$ Paed Dent 2005;6:79-83.

58. Jalevik B, Dietz W, Nóren JG. Scanning electron micrograph analysis of hypomineralized enamel in permanent first molars. Int J Paed Dent. 2005;15:233-40.

59. Americano GC, Jacobsen PE, Soviero VM, Haubek D. A systematic review on the association between molar incisor hypomineralization and dental caries. Int $\mathrm{J}$ Paediatr Dent. 2016; Apr 21:1-11.

60. Ghanim, A. et al. (2011). Molar-incisor hypomineralisation: prevalence and defect characteristics in Iraqi children. Int J Paediatr Dent. 2011 Nov;21(6):413-21.

61. Preusser SE, Ferring, Wleklinski C, Wetzel WE. Prevalence and severity of molar incisor hypomineralization in a region of Germany - a brief communication. J Public Health Dent. 2007;67(3):148-50.

62. Rood HD, Boissonade FM, Day PF. Pulpal status of hypomineralised permanent molars. Pediatr Dent 2007:29:514-520. 
63. Kotsanos N, Kaklamanos EG, Arapostathis K. Treatment management of first permanente molars in children with molar-incisor hypomineralization. Eur J Paediatric Dent 2005;4:179-184.

64. Lasfargues, JJ, Kaleka, R, Louis, JJ. A new system of minimally invasive preparations: the Si/Sta concept. Adhesion. The silent revolution in Dentistry. Quintessence Publ., Chicago-USA 2000, S. 108 -151.

65. Cefaly DF, Barata TJ, Tapety CM, Bresciani E, Navarro MF. Clinical evaluation of multisurface ART restorations. J Appl Oral Sci. 2005 Mar;13(1):15-9.

66. Frencken JE. Evolution of the the ART approach: highlights and achievements. J Appl Oral Sci. 2009; 17:78-83

67. Nyvad B, Machiulskiene V, Baelum V. Reliability of a new caries diagnostic system differentiating between active and inactive caries lesions. Caries Res. 1999 Jul;33(4):252-60.

68. Luengas-Quintero E, Frencken JE, Muñúzuri-Hernández JA, Mulder J. The atraumatic restorative treatment (ART) strategy in Mexico: two-years follow up of ART sealants and restorations. BMC Oral Health. 2013;13:42.

69. Navarro MF, Leal SC, Molina GF, Villena RS. Tratamento restaurador atraumático: atualidades e perspectivas. Rev Assoc Cir Dent 2015;69(3):289-301.

70. Frencken JE. The State of the Art of Art Restaurations. Dent Update. 2014;41(3):218-20, 222-4.

71. Roshan NM, Sakeenabi B. Survival of occlusal ART restorations in primary molars placed in school environment and hospital dental setup-one year follow-up study. Med Oral Patol Oral Cir Bucal. 2011;16(7):973-7. 
72. Garg N, Jain AK, Saha S, Singh J. Essentiality of Early Diagnosis of Molar Incisor Hypomineralization in Children and Review of its Clinical Presentation, Etiology and Management. Int J Cllin Pediatr Dent 2012;5(3):190-196.

73. Cangussu MCT, Narvai PC, Castellanos-Fernandez R, Djehizian V. A fluorose dentária no Brasil: uma revisão crítica. Cad. Saúde Pública 2002;18 (1):7-15.

74. De Menezes Abreu, DM, Leal SC, Mulder J, Frencken JE. Pain experience after conventional, atraumatic, and ultraconservative restorative treatments in 6 to 7-yrold children. Eur J Oral Sci 2011;119:163-168.

75. De Amorim RG, Leal SC, Mudler J, Creugers NHJ, Frencken JE. Amalgam and ART restorations: a controlled clinical trial. Clin Oral Invest 2014;18(1):117-24.

76. Ersin NK, Candan U, Aykut A, Onçað O, Eronat C, Kose T. A clinical evaluation of resin-based composite and glass ionomer cement restorations placed in primary teeth using the ART approach: results at 24 months. J Am Dent Assoc. 2006;137(11):1529-36.

77. Hilgert LA, de Amorim RG, Leal SC, Mulder J, Creugers NH, Frencken JE. Is high-viscosity glass-ionomer-cement a successor to amalgam for treating primary molars? Dent Mater 2014;30(10):1172-8.

78. Molina GF, Faulks D, Mazzola I, Mulder J, Frencken JE. One year survival of ART and conventional restorations in patients with disability. BMC Oral Health. $2014 ; 14: 49$.

79. Frencken JE. Evolution of ART approach: highlights and achievements. J Appl Oral Sci. 2009;17:78-83.

80. Portal Brasil. http://www.brasil.gov.br/educacao/2014/05/saiba-como-e-a-divisaodo-sistema-de-educacao-brasileiro/view. 
81. Atlas de Desenvolvimento Humano no Brasil.2013. Disponível em http://www.atlasbrasil.org.br/2013/pt/perfil udh/22939.

82. Institudo Brasileiro de Geografia e Estatística - IBGE. http://www.ibge.gov.br/home/

83. Brasil. Ministério da Saúde. Secretaria de Atenção à Saúde. Secretaria de Vigilância em Saúde. SB Brasil 2010: Pesquisa Nacional de Saúde Bucal: resultados principais / Ministério da Saúde. Secretaria de Atenção à Saúde. Secretaria de Vigilância em Saúde. - Brasília: Ministério da Saúde, 2012. 116 p. ISBN 978-85-3341987-2

84. Farag AM, Van der Sanden WJ, Abdelwahab H, Frencken JE. Survival of ART restorations assessed using selected FDI and modified ART restoration criteria. Clin Oral Investig. 2011; 15(3): 409-415.

85. Scarparo A, Zermiani TC, Ditterich RG, Pinto MHB. Impacto da Política Nacional de Saúde Bucal - Programa Brasil Sorridente - sobre a provisão de serviços odontológicos no Estado do rio de Janeiro. Cad Saude Colet, 2015;23(4): 409-415.

86. Leal SC, Oliveira TRM, Ribeiro APD. Do parents and children perceive molarincisor hypomineralization as an oral health problem? Int J Paediatr Dent. 2016 Oct 17. doi: $10.1111 /$ ipd.12271. [Epub ahead of print]

87. Gurgan S, Kutuk ZB, Ergin E, Oztas SS, Cakir FY. Four-year randomized clinical trial to evaluate the clinical performance of a glass ionomer restorative system. Oper Dent. 2015 Mar-Apr;40(2):134-43.

88. Escosteguy CC. Metodologia de ensaios clínicos randomizados. Arq Bras Cardiol 1999;72(2):139-43.

89. Santhosh KJT, Prabu D, Suhas K: Socio-behavioral variables effecting oral hygiene and periodontal status of 12 year-old schoolchildren of Udaipur district. Odontostomatol Trop 2013, 36:27-33. 
90. Peres MA, Latorre MRDO, Sheiham A, Peres KGA, Barros FC, Hernandez PG, Maas AMN, Romano AR, Victora CG. Social and biological early life influences on severity of dental caries in children aged 6 years. Community Dent Oral Epidemiol 2005; 33: 53-63.

91. Oliveira LB, Sheiham A, Bönecker M. Exploring the association of dental caries with social factors and nutritional status in Brazilian preschool children. Eur J Oral Sci 2008;116(1):37-43.

92. De Amorim RG, Figueiredo MJ, Leal SC, Mulder J, Frencken JE. Caries experience in a child population in a deprived area of Brazil, using ICDAS II. Clinical Oral Investigations 2012;16(2):513-520.

93. Sarnat BG, Schour I. Enamel hypoplasia (chronologic enamel aplasia) in relation to systemic disease: a chronologic morphologic and ethiologic classification. $J$ Am Dent Assoc 1941;28:1989-2000.

94. Koch G, Hallonsten AL, Ludwigsson N, Hansson BO, Holst A, Ullbro C. Epidemiologic study of idiopatic enamel hypomineralization on permanent teeth of Swedish children. Comm Dent Oral Epidemiol 1987;15(5):289-85.

95. Jeremias F, de Souza JF, Silva CM, Cordeiro Rde C, Zuanon AC, Santos-Pinto L. Dental caries experience and Molar-Incisor Hypomineralization. Acta Odontol Scand. 2013;71(3-4):870-6.

96. Mangum J, Crombie F, Kilpatrick NM, Manton D, Hubbard M. Surface integrity governs the proteome of hypomineralized enamel. J Dent Res; 89(10): 1160-5

97. Pascotto, R.C.; Navarro, M.F.L. Aplicações clínicas dos cimentos de ionômero de vidro. Estética em clínica odontológica Curitiba: Editora Maio, 2004.

98. Frencken JE, Van't Hof MA, Taifour D, Al-Zaher I. Effectiveness of ART and traditional amalgam approach in restoring single-surface cavities in posterior teeth of 
permanent dentitions in school children after 6.3 years. Community Dent Oral Epidemiol. 2007; 35: 207-14.

99. Kramer, PF, Pires, LAG, Tovo, MF, Kersting, TC, Guerra, S. Grau de infiltração marginal de duas técnicas restauradoras com cimento de ionômero de vidro em molares decíduos: Estudo comparativo “in vitro”. J Appl Oral Sci 2003;11(2): 114119.

100. Instruções fabricante Equia Forte ${ }^{2}$ GC. http://www.gceurope.com/pid/183/leaflet/en Leaflet.pdf.

101. Cooley RL, Train TE. Comparison of manually and mechanically mixed glass ionomers. J Prosthet Dent. 1991;66(6):773-6.

102. Luengas-Quintero E, Frencken JE, Munuzuri-Hernandéz JA, Mudler J. The atraumatic restorative treatment (ART) strategy in Mexico: two-years follow up of ARTsealants and restorations. BMC Oral Health 2003;8:13-42.

103. Mickenautsch S, Frencken JE. Utilization of the ART approach in a group of public oral health operators in South Africa: a 5-year longitudinal study. BMC Oral Health 2009;21:9-10.

104. Wang Y, Li C, Yuan H, Wong MC, Zou J, Shi Z, Zhou X. Rubber dam isolation for restorative treatment in dental patients. Cochrane Database Syst Rev 2016 Sep 20.

105. Burke FJT, Bardha JS. A retrospective, practice-based, clinical evaluation of Fuji IX restorations aged over five year placed in load-bearing cavities. Br Dent J. 2013;215(6).

106. De Amorim RG, Leal SC, Frencken JE. Survival of atraumatic restorative treatment $(A R T)$ Sealants and ART restorations: a meta-analysis. Clin Oral Invest 2012;16(2):429-4. 
ANEXOS 


\section{ANEXO A - DOCUMENTO dE APROVAÇÃO NO COMITÊ DE ÉTICA EM PESQUISA}

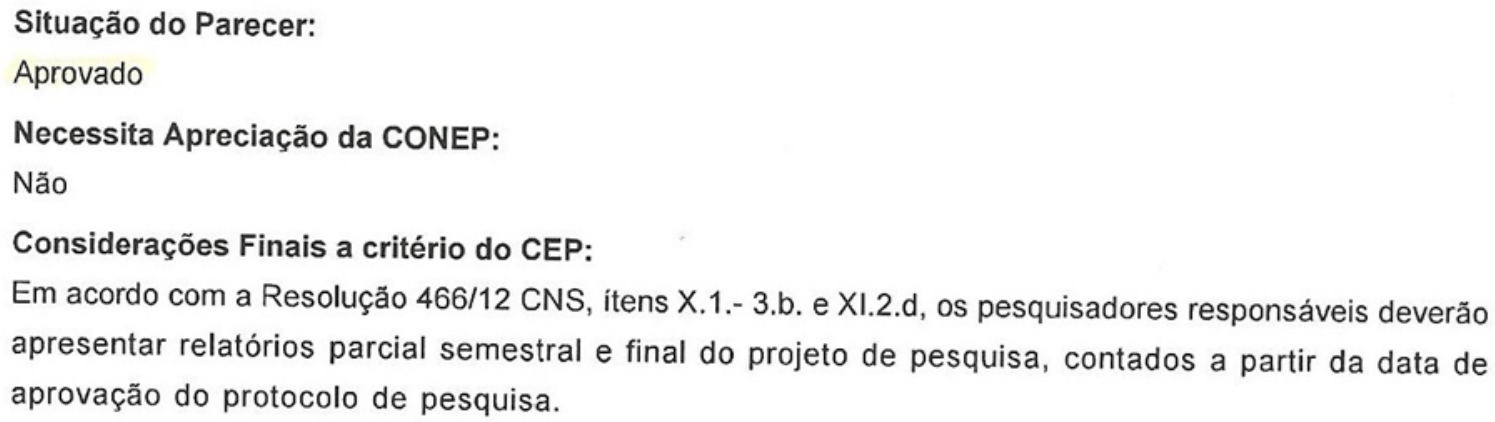


FACULDADE DE CIÊNCIAS DA

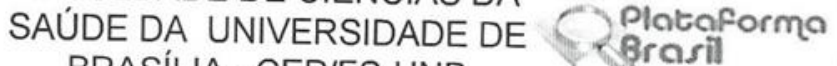
BRASÍLIA - CEPIFS-UNB

\section{PARECER CONSUBSTANCIADO DO CEP}

\section{DADOS DO PROJETO DE PESQUISA}

Título da Pesquisa: ART em dentes com MIH.

Pesquisador: JULIANA GROSSI

Área Temática:

Versăo: 2

CAAE: 39518314.4 .0000 .0030

Instituição Proponente: Faculdade de Ciências da Saúde da Universidade de Brasilia

Patrocinador Principal: Financiamento Próprio

\section{DADOS DO PARECER}

Número do Parecer: 999.923

Data da Relatoria: $18 / 03 / 2015$

\section{Apresentação do Projeto:}

Este estudo foi desenvolvido para avaliar a performance clinica do Tratamento Restaurador Atraumatico (ART)em dentes portadores de Hipomineralizacao molar incisivo(MIH). MIH e definida como um defeito qualitativo de desenvolvimento que envolve 1 ou 4 primeiros molares permanentes com ou sem o envolvimento dos incisivos permanentes. Os dentes cavitados e portadores de $\mathrm{MIH}$ foram selecionados por meio de estudo epidemiologico em criancas de 8 a 11 anos e restaurados com cimento de ionomero de vidro da marca EQUIA (GC), atraves da tecnica ART. Espera-se que as restauracoes ART tenham boa performance clinica evitando procedimentos mais invasivos e complexos nessas criancas como endodontia, extracoes, uma vez que esse pacientes nao tem acesso facil ao dentista.

A Hipomineralizacao Molar-Incisivo $(\mathrm{MIH})$ e definida como uma alteracao de desenvolvimento relativamente comum caracterizada por defeitos na mineralizacao do esmalte dentario nos primeiros molares e incisivos permanentes.Alguns autores defendem que os defeitos no esmalte dentario de dentes afetados por $\mathrm{MIH}$ resultam de uma variedade de fatores ambientais interagindo sistemicamente no periodo de desenvolvimento natal, perinatal e pos-natal da crianca, assim como condicoes medicas dessas criancas nesse periodo, a citar: catapora, febre alta, uso frequente de antibioticos etc.A Hipomineralizacao MolarIncisivo esta associada a varios problemas dentarios entre eles: acumulo de placa, rapido desenvolvimento de carie, bem como aumento de sua

Endereço: Faculdade de Ciências da Saúde - Campus Darcy Ribeiro

Bairro: Asa Norte CEP: $70.910-900$

UF: DF Municipio: BRASILIA

E-mail: cepfsunb@gmail.com 
ANEXO B - TERMO DE CONSENTIMENTO LIVRE E ESCLARECIDO

\author{
$\square$ \\ Universidade de Brasilia \\ TERMO DE CONSENTIMENTO LIVRE E ESCLARECIDO
}

Eu, Juliana de Aguiar Grossi responsável pela pesquisa "Tratamento da hipomineralização molarincisivo: desafios clínicos e soluçð̃es" e orientada pela Prof. Dra. Soraya Coelho Leal, estou fazendo um convite para seu filho ou dependente possa participar como voluntário deste estudo que tem como objetivo testar a aplicabilidade do tratamento restaurador atraumático - ART, que é um tratamento que pode ser realizado na escola e não precisa do motorzinho nem da broca. As crianças que apresentam defeitos no esmalte possuem o dente mais fácil de cariar e quebrar. Esses dentes chamamos de dentes com hipomineralização molar-incisivo. As crianças selecionadas para esta pesquisa serão aquelas com esses defeitos no esmalte e necessidade de tratamento nos primeiros molares permanentes. Elas serão tratadas na escola onde estudam, inicialmente. Os dentes cariados serão limpos com instrumentos de dentista parecidos com uma colher e secos com bolinhas de algodão. Caso a criança sinta algum desconforto neste momento, a anestesia local pode ser necessária. Poderá haver pequeno desconforto decorrente dos exames e restaurações a serem realizadas. Na tentativa de minimizá-los, os procedimentos serão feitos em maca e com materiais levados pela examinadora responsável. Caso a criança sinta dor durante a remoção de cárie com curetas, será ministrada anestesia local para remover o incômodo na criança diminuindo stress psicológico durante o atendimento. Não será utilizado motorzinho nem brocas. Após limpar o buraco que a cárie deixou, iremos tampar a cavidade com uma massinha da cor do dente. Esse é o Tratamento Restaurador Atraumático onde ao invés do motorzinho de dentista usamos curetas. É um tratamento muito utilizado em crianças gerando menos stress durante o atendimento. Será feita também, 02 avaliaçð̃es, na própria escola com espelhinho, para ver o sucesso das restaurações : a primeira após 06 meses e a outra depois de 12 meses após a criança ser atendida na escola.

Esclarecemos que a remoção da cárie o mais rápido possível seguida da restauração é muito importante para a saúde geral do seu filho, pois a cárie nao tratada causa no futuro infeç̧б̃es no osso do dente e gengiva, muita dor e inchaço do rosto da criança. O dente que estiver muito destruído e nao poder ser mais restaurado na escola será encaminhado para tratamento no HUB.

Durante todo o periodo da pesquisa você tem o direito de tirar qualquer dúvida ou pedir qualquer outro esclarecimento, bastando para isso entrar em contato, com algum dos pesquisadores ou com o Conselho de Ética em Pesquisa. As informaç̃̃es desta pesquisa serão confidencias, e serão divulgadas apenas em eventos ou publicações científicas, não havendo identificação do seu filho ou dependente, sendo assegurado o sigilo sobre sua participação (confidencialidade). Não há riscos previsiveis ao voluntário nesse estudo. Sua participação é voluntária e sem penalidades, caso se negue a participar.

A participação na pesquisa não será remunerada de nenhuma forma e não lhe trará nenhuma despesa financeira. Todas as despesas da pesquisa serão financiadas pela própria pesquisadora. Caso o participante se sinta lesado com a pesquisa, fica a ele garantido direito de indenização por parte dos pesquisadores. Se houver alguma dúvida sobre a pesquisa, o voluntário poderá entrar em contato com a pesquisadora responsável Dra. Juliana de Aguiar Grossi pelo telefone (61) 82059954 ou com a orientadora Prof Soraya Leal pelo telefone (61)81184949 e se preferir, pelo e-mail: juliana.grossi@gmail.com.

Caso o (a) senhor (a) queira apresentar reclamaçð̃es em relação a participação na pesquisa poderá entrar em contato com o Comitê de Ética em Pesquisa em Seres Humanos (CEP), da Faculdade de Ciências da Saúde da Universidade de Brasília pelo telefone 31071947 ou e-mail: cepfsunb@gmail.com. Horário de atendimento ao público : de segunda a sexta feira de $10 \mathrm{hs}$ as $12 \mathrm{hs}$ e 13:30 as 15:30hs. O CEP foi criado para defender os interesses dos sujeitos da pesquisa em sua integridade e dignidade e para contribuir no desenvolvimento da pesquisa dentro de padrôes éticos (Resolução n 466/12 Conselho Nacional de Saúde). Senhor(a).

Este documento foi elaborado em duas vias, uma ficará com o pesquisador responsável e outra com o

Após a leitura (ou a escuta da leitura) deste documento e ter tido a oportunidade de conversar com o pesquisador responsável, para esclarecer todas as minhas dúvidas, acredito estar suficientemente informado para firmar este TERMO DE CONSENTIMENTO LIVRE E ESCLARECIDO, ficando claro para mim que minha participação é voluntária e que posso retirar este consentimento a qualquer momento sem penalidades ou perda de qualquer benefício. Estou ciente também dos objetivos da pesquisa, dos procedimentos aos quais

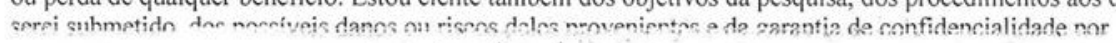




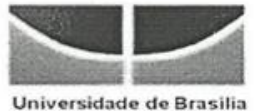

força de sigilo profissional (Art. 9 do Código de Ética Odontológica) e esclarecimentos sempre que desejar. Diante do exposto expresso minha concordância de espontânea vontade em participar deste estudo.

Brasilia, de de

Assinatura do pai ou responsável pelo participante da pesquisa

Assinatura da pesquisadora responsável 
ANEXO C - TERMO DE ASSENTIMENTO DA CRIANÇA

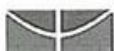 \\ Universidade de Brasília \\ Departamento de Odontologia
}

Termo de Assentimento

Você está sendo convidado a participar da pesquisa intitulada "Tratamento da hipomineralização molar-incisivo: desafios clínicos e soluções" sob minha responsabilidade e da orientadora Professora Dra. Soraya Coelho Leal. Seus pais permitiram que você participasse desta pesquisa.

Queremos saber como as massinhas da cor do dente, que chamamos de cimento de ionômero de vidro, vão se comportar depois que colocarmos no dente . Vai ser assim:

O dentista vai ver se tem algum buraquinho no seu dente. Depois vai tirar a cárie do seu dente usando uma colherzinha. Por último, vai colocar uma massinha branca para tampar o buraquinho do dente e tirar uma foto do seu dentinho.

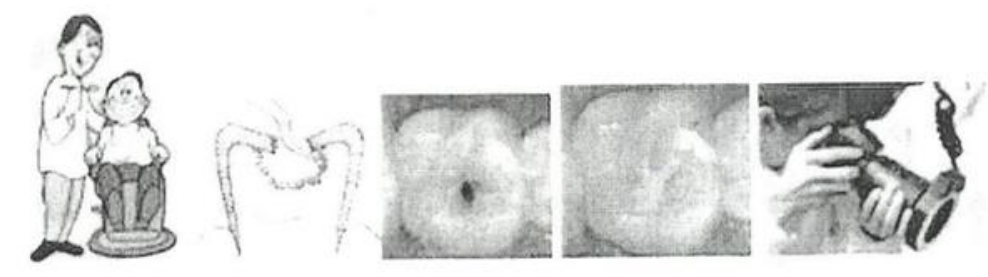

Mas, você não é obrigado a participar da pesquisa, e pode desistir quando quiser. Se você tiver alguma dúvida, pode perguntar para a Dra. Juliana Grossi pelo telefone 82059954 ou, se preferir pelo e-mail juliana.grossi@gmail.com

$\mathrm{Eu}$,

aceito participar da pesquisa "Tratamento da hipomineralização molar-incisivo: desafio clínico e soluções", que tem por objetivo ver como se comporta uma massinha chamada ionômero de vidro para obturar meus dentes. Entendi que posso dizer "sim" e participar, mas que, a qualquer momento, posso dizer "não" e desistir, sem ninguém ficar bravo. Os pesquisadores tiraram minhas dúvidas e conversaram com os meus responsáveis. Recebi uma cópia deste termo de assentimento e li e concordo em participar da pesquisa. 


\section{ANEXO D - QUESTIONÁRIO SÓCIO-ECONÔMICO}

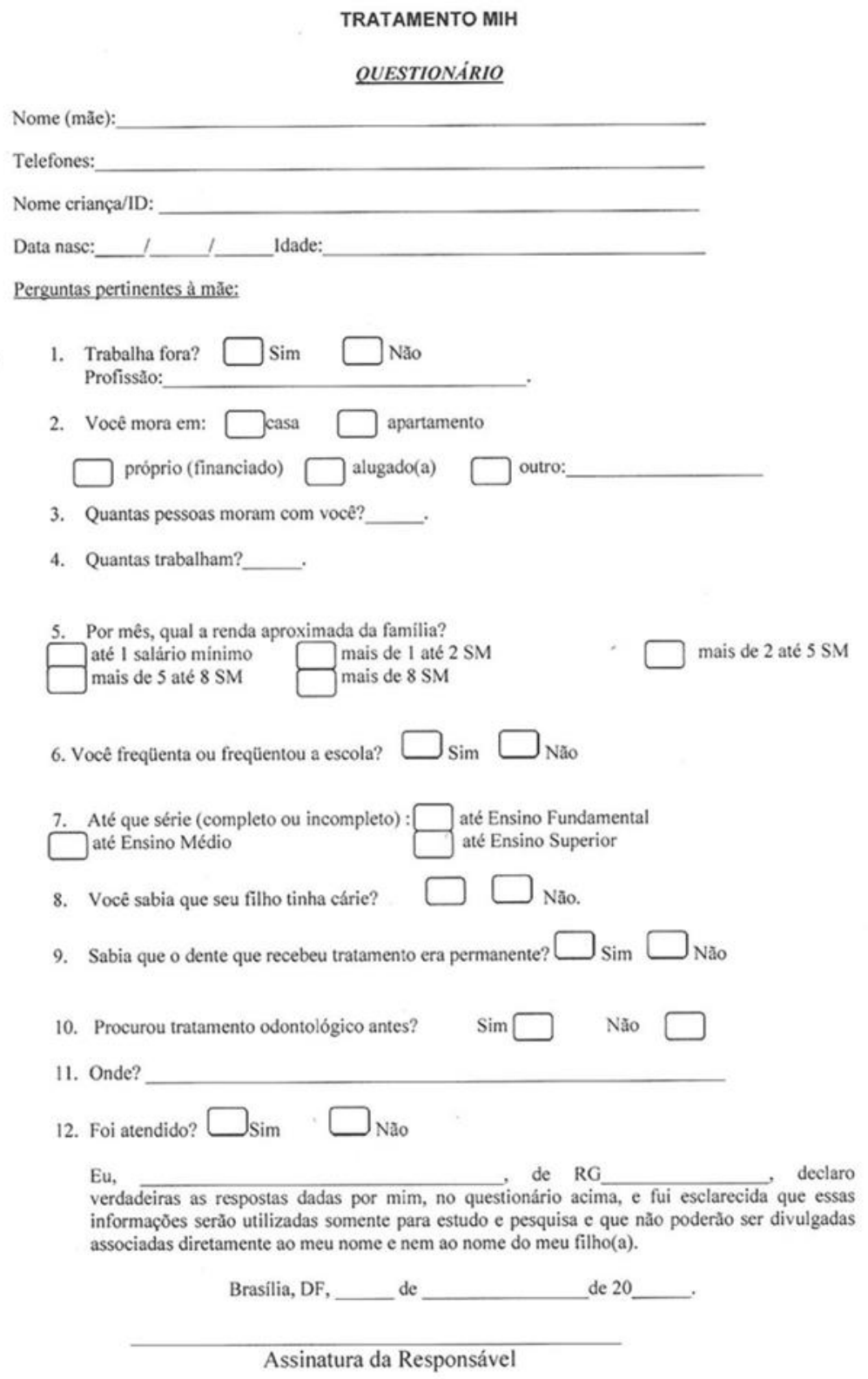




\section{ANEXO E - FICHA DE ATENDIMENTO CLÍNICO}

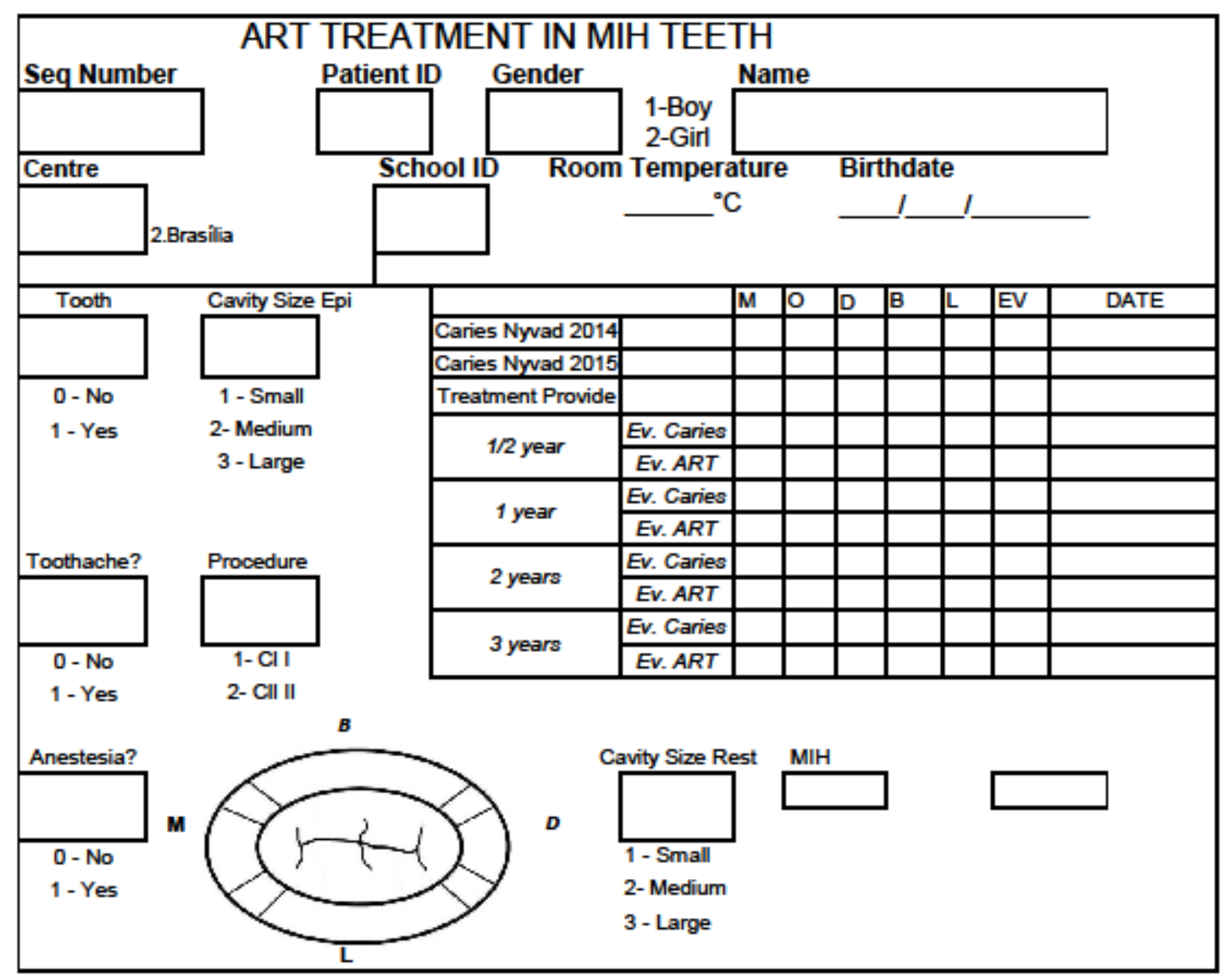


